\author{
Military Technical College \\ Kobry El-Kobbah, \\ Cairo, Egypt.
}

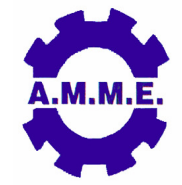

\title{
EXPERIMENTAL AND NUMERICAL STUDIES ON HEAT TRANSFER AND FLUID FLOW IN A DUCT FITTED WITH INCLINED BAFFLES
}

\author{
W. A. El-Askary ${ }^{*}$ and A. Abdel-Fattah ${ }^{\star *}$
}

\begin{abstract}
Experimental and numerical studies of heat transfer and the frictional head loss of turbulent flow in a duct with a heated upper surface are performed in the present paper. Four different arrangements are considered (case 1: without baffles, case 2: one perforated baffle on the upper wall and one solid baffle on the lower wall, case 3: one perforated baffle on the upper wall and one perforated baffle on the lower wall and case 4: two perforated baffles on the upper wall). A numerical code developed by the present authors is simultaneously presented including four different turbulence models; namely: the standard $k-\varepsilon$, the modified $k-\varepsilon$ including streamline curvature, the renormalization group model (RNG model) and the $\mathrm{v}^{2}-f$ model. The last one shows the best verified results compared with the other models, so $\mathrm{v}^{\prime 2}-f$ model is considered in all computations. The presence of baffles enhanced the heat transfer relative to the smooth-wall duct. Finally, pressure loss and temperature drop along the test section are employed to evaluate the hydraulic and thermal performances of the duct at different Reynolds numbers. It is found experimentally and numerically that the perforation and position of baffles have a significant effect in the pressure loss and internal cooling of the duct.
\end{abstract}

\section{KEY WORDS}

Heat transfer enhancement; Turbulent flow; Pressure loss; Rectangular duct flow; Inclined baffle; Numerical simulation

Assoc. Professor; Mechanical Power Engineering Dept., Faculty of Engineering, Menoufiya University (Corresponding author), Tel.: +2-01005255817, +2-048-3486965; Fax: +2-048-2235695. Email address: wageeh elaskary@yahoo.com.

** Mechanical Power Engineering Dept., Faculty of Engineering, Menoufiya University 


\section{NOMENCLATURE}

\begin{tabular}{|c|c|}
\hline$c_{1}, c_{2}, c_{\mu}$ & Empirical constants of the $k-\varepsilon$ model \\
\hline$C_{p}$ & Wall-pressure coefficient, $C_{p}=\left(\bar{p}-\bar{p}_{r e f}\right) / 0.5 \rho U_{\text {in }}^{2}$ \\
\hline$D_{h}$ & Hydraulic diameter ( $D_{h}=4 \times$ cross-sectional area/wetted perimeter), $m$ \\
\hline $\begin{array}{l}d \\
\bar{f}, f\end{array}$ & $\begin{array}{l}\text { Hole diameter in the baffle, } m \\
\text { Dimensional and dimensionless variable related to energy } \\
\text { redistribution in the equation of the scalar velocity scale } \mathrm{v}^{\prime 2}\end{array}$ \\
\hline$f_{c}$ & Friction factor of the duct \\
\hline$H$ & Duct height, $m$ \\
\hline $\bar{k}$ & Turbulence kinetic energy, $\mathrm{m}^{2} / \mathrm{s}^{2}$ \\
\hline$l$ & Baffle length, $m$ \\
\hline $\bar{k}, k$ & Dimensional and dimensionless turbulent kinetic energy \\
\hline $\bar{L}, L$ & Dimensional and dimensionless-length scale used in $\mathrm{v}^{\prime 2}-f$ model \\
\hline$L^{*}$ & Characteristic length used in the $\mathrm{v}^{\prime 2}-f$ model \\
\hline $\mathrm{Nu}$ & Channel centerline Nusselt number \\
\hline$N u_{0}$ & $\begin{array}{l}\text { Nusselt number for fully developed pipe flow } \\
\text { at the same Reynolds number }\end{array}$ \\
\hline$P_{k}$ & Production of the kinetic energy, $\mathrm{N} / \mathrm{m}^{2} / \mathrm{s}$ \\
\hline $\operatorname{Pr}$ & Laminar Prandtl number \\
\hline $\mathrm{Pr}_{t}$ & Turbulent Prandtl number \\
\hline $\bar{p}$ & Local pressure, $\mathrm{N} / \mathrm{m}^{2}$ \\
\hline $\bar{p}_{r e f}$ & Reference pressure, $\mathrm{N} / \mathrm{m}^{2}$ \\
\hline$Q$ & Flow rate, $m^{3} / \mathrm{sec}$ \\
\hline$q^{o}$ & Wall-heat flux, watt \\
\hline $\operatorname{Re}$ & Reynolds number, $\operatorname{Re}=U_{\text {in }} D_{h} / v$ \\
\hline $\operatorname{Re}_{t}$ & Turbulent REYNOLDS number, $\operatorname{Re}=U_{i n} D_{h} / v_{t}$ \\
\hline $\bar{T}$ & Local temperature, ${ }^{\circ} \mathrm{C}$ \\
\hline $\bar{T}^{\prime}$ & Temperature fluctuation, ${ }^{\circ} \mathrm{C}$ \\
\hline$t$ & Baffle thickness, $m$ \\
\hline$U_{\text {in }}$ & Average velocity of duct inlet $\left(U_{i n}=\frac{Q}{W \times H}\right), \mathrm{m} / \mathrm{s}$ \\
\hline $\bar{u}, \overline{\mathrm{v}}$ & Mean velocity components in $\bar{x}, \bar{y}$ directions, respectively, $\mathrm{m} / \mathrm{s}$ \\
\hline $\bar{u}^{\prime}$ & Velocity fluctuation in streamwise direction, $\mathrm{m} / \mathrm{s}$ \\
\hline$\overline{\mathrm{v}}^{\prime}, \mathrm{v}^{\prime}$ & Dimensional and dimensionless turbulent velocity scale, \\
\hline$W$ & Duct width, $m$ \\
\hline $\bar{x}, \bar{y}$ & Coordinates in streamwise and transverse directions, $m$ \\
\hline
\end{tabular}

\section{Greek symbols}

$\bar{\beta} \quad$ Coefficient of thermal expansion $\left(\beta=-(\partial \rho / \partial T)_{p}\right), \mathrm{kg} / \mathrm{m}^{3} /{ }^{\circ} \mathrm{C}$ 
$\varepsilon \quad$ Turbulence-energy dissipation rate, $\mathrm{N} / \mathrm{m}^{2} / \mathrm{sec}$

$\mu, \mu_{t} \quad$ Laminar and turbulent dynamic viscosity, respectively, N.s $/ \mathrm{m}^{2}$

$v, v_{t} \quad$ Laminar and turbulent kinematic viscosity, $(v=\mu / \rho), \mathrm{m}^{2} / \mathrm{s}$

$\rho \quad$ Fluid density, $\mathrm{kg} / \mathrm{m}^{3}$

$\bar{\tau}, \mathrm{T} \quad$ Dimensional and dimensionless turbulent time scale

$\tau^{*} \quad$ Characteristic turbulent time scale used in the $\mathrm{v}^{\prime 2}-f$ model

$\sigma_{k}, \sigma_{\varepsilon} \quad$ Turbulence-model constants

\author{
Subscript \\ ref Reference value \\ i, in Inlet condition \\ $i, j \quad$ Component $i, j$ of a vector
}

\title{
INTRODUCTION
}

In the cooling duct or duct heat exchanger design, rib, fin or baffle turbulators are often employed in order to increase the convective heat transfer rate leading to the compact heat exchanger and increasing the efficiency. For decades, rib turbulators have been applied in high-performance thermal systems due to their high thermal loads. The cooling or heating air is supplied into the passages or ducts with several ribs to increase the stronger degree of cooling or heating levels over the smooth wall channel. The use of rib turbulators completely results in the change of the flow field and hence the variation of the local convective heat transfer coefficient.

Insertion of baffles in heat transfer devices is popular to promote better mixing of the coolant and increase cooling performance. Applications of the inclined baffles may be in the large land-based gas turbine blade coolant path, air-cooled solar collectors, heat exchangers, and power plants. The baffle plate is usually attached to the heated surface to augment heat transfer by providing additional area for heat transfer and better mixing. To augment the heat transfer coefficient of gases in internal flow, the following techniques are generally used, see Dutta and Dutta [1]: (i) Boundary layer disturbance caused by periodically placed ribs on the heat transfer surface. These ribs are small and do not disturb the core pressure drop increase for low to moderate Reynolds numbers. (ii) Impingement cooling uses high velocity jets to cool the surface of interest. However, often a large region needs to be cooled and multiple jets are required. (iii) The third technique is the use of internal flow swirls or tape twisters. This technique creates a significant amount of bulk flow disturbance, and pressure drop may be higher compared to the increase in heat transfer coefficient. Inclined solid baffles may be considered as a combination of ribs and channel inserts. Baffles also create bulk flow disturbance, but unlike tapes or swirls, baffles are discrete objects. Therefore, the flow disturbance created by baffles may be localized, but more intense. Usually the baffle plate is attached to the thermally active surface to augment heat transfer by providing additional fin-like surface area for heat transfer and better mixing. The baffles are big enough to disturb the core flow, but like ribs, they are mounted on or near the heat transfer surface and can be periodic in nature. Perforations in inclined baffles create a multiple jet impingement 
condition and thus create a situation where all three major heat transfer coefficient enhancement techniques work in unison. Previously, experimental results were published with baffle plates, perpendicular to the flow direction. Among important studies, Berner et al. [2] obtained mean velocity and turbulence results in flow over baffles; and Habib et al. [3] investigated heat transfer and flow over perpendicular baffles of different heights. But these works mainly emphasized on baffles that were perpendicular to the flow direction and for that reason penalties (friction factor) were higher than the improvements (heat transfer augmentation).

However, it is possible to obtain enhanced heat transfer with comparably less frictional head loss by inserting inclined baffles in the flow path. Inclined baffles may be considered as a combination of ribs and channel inserts. These baffles are big enough to disturb the core flow, but like ribs, they are mounted on or near the heat transfer surface. Moreover, inclined perforated baffles contain circular holes, which facilitate jet impingement toward the heat transfer surface. Hence by utilizing inclined perforated baffles, the three major heat transfer augmentation techniques can be combined for effective cooling.

Different ranges of Reynolds number are experimentally explored by Dutta and Dutta [1], Lin [4] and Kurtbas [5] to report the enhancement of heat transfer with inclined solid and perforated baffles. In those studies, the effects of baffle size, position, and orientation were studied for internal cooling heat transfer augmentation. It has been shown that the inclined perforated baffle attached to the heated surface works much better than the corresponding arrangement with solid baffles; see (Dutta and Dutta [1]). The inclined perforated baffle allows the jet impingement toward the heated surface to augment the heat transfer. Apart from increasing the perturbation of flow field, the duct's flow field with baffles, which is similar to a backward-facing step flow field, is very helpful to heat transfer. The pressure drop and heat transfer rate are strongly increased with the presence of a baffle and turned flow compared with a straight duct. The same basics of heat transfer enhancement have been experimentally considered by Chandra et al. [6] to measure the heat transfer and friction characteristics of a fully developed turbulent flow in channels with transverse vertical ribs on all walls. They found that the heat transfer coefficient and friction factor results were enhanced with the increase of the number of ribbed walls. An experimental study of heat transfer and friction in a rectangular section duct with fully and half perforated baffles was performed by Karwa and Maheshwari [7]. However, the baffles used were installed vertically causing high pressure losses with the heat transfer augmentation.

Numerical studies also had been widely considered, see Shaeri and Yaghoubi [8], who used RNG based $k-\varepsilon$ turbulence model to predict turbulent flow parameters. Flow and heat transfer characteristics were presented for low Reynolds numbers ranged from 20000 to 40000 . The computations were validated with experimental studies of previous investigators and agreements were observed. On the other hand, calculation of the turbulent flow field and heat transfer in three-dimensional (3D) ribbed ducts was performed by Ooi et al. [9]. It was found that heat transfer predictions obtained using the $v^{2}-f$ turbulence model produce only fair agreement with experimental data for the $3 \mathrm{D}$ ribbed duct. On the wall of the duct where ribs exist, predicted heat transfer agrees well with experimental data for all 
configurations. Heat transfer predictions on the smooth-side wall do not concur with the experimental data.

Nasiruddin and Siddiqui [10] used the commercial CFD software FLUENT 6.1 to simulate the heat transfer enhancement in a heat exchanger tube by installing a baffle. The standard $k-\omega$ was used as a turbulence model. The effect of baffle size and orientation on the heat transfer enhancement was studied in detail. Three different baffle arrangements were considered. The results of Nasiruddin and Siddiqui [10] showed that for the vertical baffle, an increase in the baffle height causes a substantial increase in the Nusselt number but the pressure loss is also very significant. For the inclined baffles, the results showed that the Nusselt number enhancement is almost independent of the baffle inclination angle. To examine effects of baffle on flow and heat transfer distributions on laminar forced convection flow adjacent to backward-facing step in rectangular duct Nie et al. [11] performed numerical simulations. A baffle was mounted onto the upper wall and its distance from the backward-facing step was varied. The Reynolds number based on the double height of the duct upstream of the step was equal to 343. Nie et al. [11] found that a baffle mounted onto the upper wall increased the magnitude of maximum Nusselt number at the stepped wall. They also noticed that the maximum Nusselt number on the stepped wall develops near the sidewall, and it moves further downstream as the location of the baffle moves in the streamwise direction. Further numerical studies were also considered by Luviano-Ortiz et al. [12] concerning heat transfer and fluid dynamics analysis of a horizontal channel with periodic insertions of heated blocks, having curved deflectors to direct the laminar flow. The investigated heat transfer coefficient was compared with that of the horizontal channel without deflectors. The results showed that the heat transfer coefficient was larger as compared to that of the case without deflectors.

Because of the developments of accurate measuring devices Gajusingh et al. [13] conducted an experimental study to investigate the impact of a rectangular baffle inside a square channel. Particle Image Velocimetry (PIV) was used to measure the two-dimensional velocity fields for two Reynolds numbers in the fully turbulent regime. The changes to the flow structure due to the insertion of a baffle were quantified by a direct comparison with the flow structure in the absence of a baffle, under similar conditions. The results showed that the turbulent velocities are enhanced by a factor of two to three and the rates of energy production and dissipation are enhanced by more than an order of magnitude when a baffle is inserted in the channel.

A numerical investigation on periodic laminar flow and heat transfer behaviors in a three-dimensional isothermal-wall square duct fitted with $30^{\circ}$ angled baffles on lower duct wall only was presented by Kwankaomeng et al [14]. The computations based on a finite volume method with the SIMPLE algorithm have been conducted for the fluid flow in terms of Reynolds numbers ranging from 100 to 2000. The study showed that the longitudinal vortex flow created by the baffle helps to induce impinging flows over the baffle trailing end sidewall and the inter-baffle cavity. This led to a drastic increase in heat transfer rate over the test duct. The computational results revealed that the Nusselt number ratio and the maximum thermal enhancement factor values for using the angled baffle are, respectively, found to be about 7.9 and 3.1 at $\mathrm{Re}=2000$. 
Promvonge [15] conducted an experimental research to assess turbulent forced convection heat transfer and friction loss behaviors for airflow through a channel fitted with a multiple $60^{\circ} \mathrm{V}$-baffle turbulator. The air flow rate was in terms of Reynolds numbers based on the inlet hydraulic diameter of the test channel ranging from 5000 to 25,000 . The experimental results show that the V-baffle provides the drastic increase in Nusselt number, friction factor and thermal enhancement factor values over the smooth wall channel due to better flow mixing from the formation of secondary flows induced by vortex flows generated by the V-baffle. On the other hand, Nasr et al. [16] performed experimental and numerical studies in a cold duct to investigate only the pressure recovery coefficient along the wall of a rectangular channel fitted by inclined-perforated and solid baffles for isothermal flow. The computations were an extension to that of El-Askary and Nasr [17]. Two baffles of same overall size are used in the experiment. The upstream baffle is attached to the top surface, while the position, orientation, and the shape of the other baffle are varied. Experimental results showed that the pressure recovery distribution is strongly affected by the position, orientation, and geometry of the second baffle plate. A complimentary experimental study was performed by Dutta and Hossain [18] to investigate the local heat transfer characteristics and the associated frictional head loss in a rectangular channel with inclined solid and perforated baffles. The upstream baffle was attached to the top heated surface, while the positions, orientations and the shapes of the other baffle were varied to identify the optimum configuration for enhanced heat transfer. They found that the inline placement of baffles augments the overall heat transfer significantly by combining both jet impingement and the boundary layer separation.

\section{Aim of the Present Study}

It is found from the literature that limited numerical as well experimental researches exist for the case where inclined solid or perforated-type baffles are arranged on the top and bottom duct walls with the presence of a turbulent fluid flow. Therefore, numerical studies on the effect of baffles type on heat transfer and pressure drop are presented here and comparing the results with the only experimental data measured also by the present authors.

The main objective of the present study is to augment both local and global heat transfer behavior of a gaseous fluid (air) by placement of two inclined baffles. In this study, we present experimental and numerical heat transfer and fluid flow results with the presence of two inclined baffles where the upstream perforated baffle is mounted on the heated top surface and the second (solid or perforated) baffle is either fixed to the insulated bottom surface or to the heated top surface. Depending on the position, orientation and the form of the second baffle, we have considered three different arrangements for this study. Since the flow disturbances and wakes generated by the upstream inclined baffle can potentially affect the performance of the downstream baffle, an average heat transfer performance is considered to cover the entire heated length. 


\section{EXPERIMENTAL SETUP}

A schematic view of the experimental system is shown in Fig. 1. The experimental apparatus mainly includes several sections: upstream section (7), test section (8) and outlet section. The test section is a rectangular duct, and it is made of four $3 \mathrm{~mm}$ steel plates. An electrical heater is laid on the outside surface of the top steel plate. The electric voltage and current across the heater are kept constant. In this experiment, air flow-rate can be changed by adjusting a manual valve (4). By changing the flow rate at different values, the inflow velocity and hence the Reynolds number can be changed. The main measurement parameters include inlet and outlet bulk air temperature, plate temperature distribution, pressure drop through the heater, pressure distribution along the unheated lower wall, air flow rate and the voltage and current. The thermocouples are mounted on the inner surface of the upper wall of the test section. The temperature readings from thermocouples are all recorded after reaching steady state by using a computer-controlled data acquisition system. Air flow rate is measured by a calibrated orifice meter (5); see El-Askary and Nasr [17].

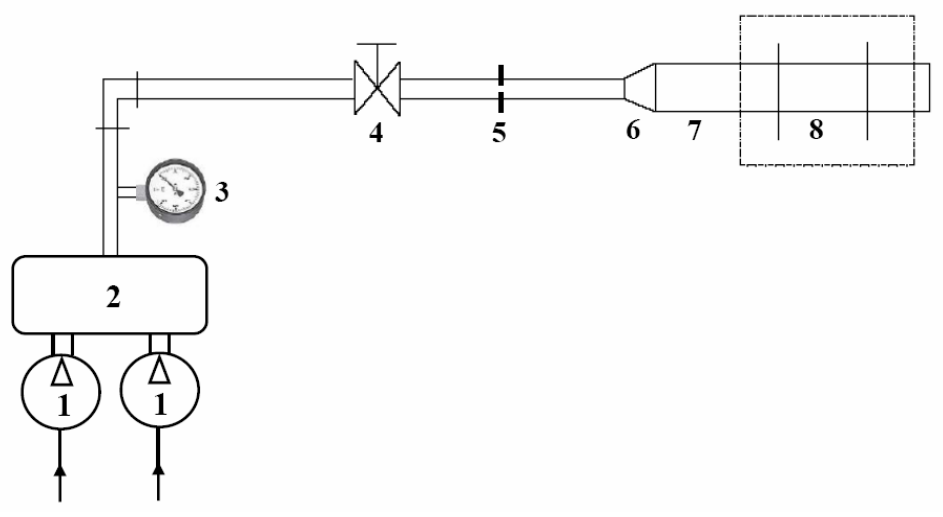

Fig. 1. Schematic view of the experimental apparatus (not to scale).

A brief description is provided as follows for the interest of completeness. The dry and cooled airflow $\left(23^{\circ} \mathrm{C}\right)$ is guided through a set of pressure regulator and filtering unit, a discharge orifice meter and a control valve where the discharge rate of air is metered and adjusted. With the predefined discharge rate the Reynolds number of the flow can be computed. The detailed heated surface temperature distribution is measured through calibrated thermocouples installed on the inner surface of the upper heated floor. The surface pressure distribution along the other lower face surface is also measured by multi-tube manometer.

Typical presentations of the duct with installed bluff baffles (e.g., one perforated and the other solid one) modeled in this study are shown in Fig. 2. The airflow is considered to be steady and turbulent with constant properties. Moreover, air velocities are such that forced convection is the dominant heat transfer mechanism between installed plates as well as the upper heated surface of the duct and ambient air. The cross-section of the smooth channel (width $W \times$ height $H$ ) is $12 \mathrm{~cm} \times 5 \mathrm{~cm}$ that has an aspect ratio of 2.4. All measurements are done along the centerline of 
the rectangular channel. The geometrical parameters, the heat transfer and pressure distribution results are presented in terms of the channel height $(\mathrm{H}=5 \mathrm{~cm})$, whereas, the Reynolds number of flow is presented in terms of channel hydraulic diameter, $D_{h}$ $\left(D_{h}=7.06 \mathrm{~cm}\right)$. Two screw compressors (1) draw air and compress it in a storage tank (2) from which the air passes through this rectangular channel through an upstream cross-section converter and flow straighteners.

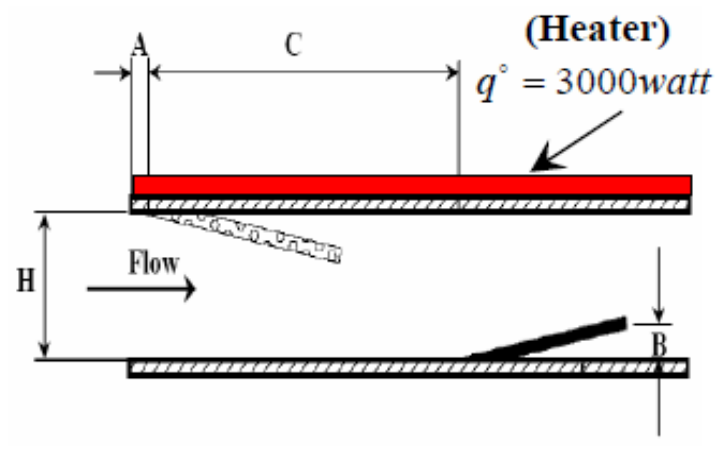

(a)

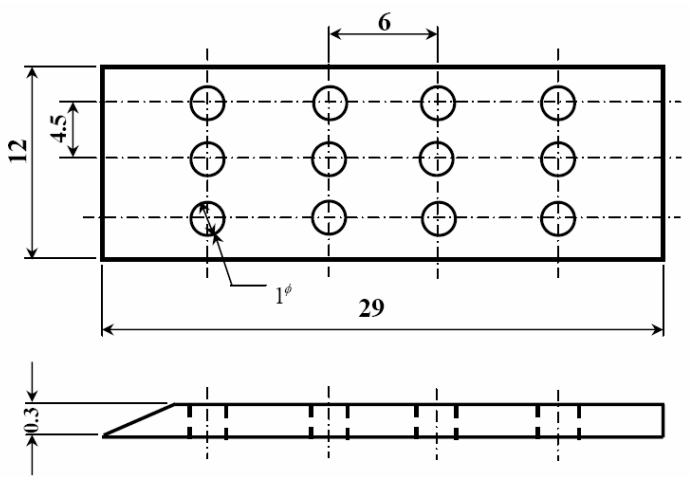

(b)

Fig. 2. (a) Schematic view of the tested duct with installed baffles (e.g., case 2) (b) Geometry of the perforated baffle plate (dimensions in $\mathrm{cm}$.) (Not to scale).

This air-flow develops through a $35 \mathrm{H}$ long unheated entrance and the exit is at a $5 \mathrm{H}$ distance downstream of the heated test section. The heated test section is $20 \mathrm{H}$ long, and is instrumented on the top surface (12 cm wide) with calibrated thermocouples, while the insulated lower one with pressure tapings to measure the wall pressure distribution. Commercial fiberglass insulation is used at the exterior sides to minimize thermal energy leakage. Stainless steel foil heaters are connected to a voltage controller to provide uniform heat flux boundary condition. These foil heaters are aligned perpendicular to the flow direction similar to a configuration used by Dutta and Dutta [1]. An isoflux heater is mounted on the upper surface of the test section; the other three sides are unheated and properly insulated. Seven J-type thermocouples are laid along the channel centerline of the upper wall. The thermocouples are calibrated against data acquisition system. The calibration is found to be a linear fit relation between the voltage reading and the measured temperature. The linear relation reads: $V=0.04 T-0.2$, where $\mathrm{V}$ is measured by milivolt and the temperature $T$ is scaled with degree centigrade.

Both (steel) solid and perforated baffles utilized in the present study are of the same overall size (length $l=29 \mathrm{~cm}$, width $W=12 \mathrm{~cm}$ and thickness $t=3 \mathrm{~mm}$ ). The schematic view of the perforated baffles is given in Fig. 2 (b). The leading edges of the baffles are kept sharp to reduce the flow disturbance by the protruding edge. All perforated baffles have uniform holes of diameter $d=1 \mathrm{~cm}$.

A total of three baffles, two perforated baffles and one solid are fabricated and used. The locations of these baffles are presented in Table 1 for different studied test cases. In all arrangements, constant inclination angle of five degrees is maintained for both baffles. This small inclination angle keeps these plates streamlined with the flow, and hence they avoid major flow blockage, see Dutta and Hossain [18]. 
Table 1 Different baffle configurations used in the experiments, see Fig. (2).

\begin{tabular}{|c|c|l|l|c|}
\hline $\begin{array}{c}\text { Case } \\
\text { study }\end{array}$ & $\boldsymbol{C}(\mathbf{c m})$ & Baffles Type & $\begin{array}{c}\text { Attachment of } \\
\text { Baffles to surfaces }\end{array}$ & $\begin{array}{c}\text { Fixed } \\
\text { dimension } \\
\text { s (cm) }\end{array}$ \\
\hline 1 & - & Without Baffles & - & - \\
\hline 2 & 44.5 & $\begin{array}{l}\text { One perforated } \\
\text { and one Solid }\end{array}$ & $\begin{array}{l}\text { One perforated up and } \\
\text { One solid down }\end{array}$ & $\begin{array}{c}\mathrm{A}=\mathbf{1 . 2 5} \\
\mathrm{B}=\mathbf{2 . 5 0}\end{array}$ \\
\hline 3 & 44.5 & Two perforated & $\begin{array}{l}\text { One perforated up and } \\
\text { the perforated down }\end{array}$ & $\begin{array}{c}\mathrm{A}=\mathbf{1 . 2 5} \\
\mathrm{B}=\mathbf{2 . 5 0}\end{array}$ \\
\hline 4 & 44.5 & Two perforated & Upper wall & $\begin{array}{c}\mathrm{A}=\mathbf{1 . 2 5} \\
\mathrm{B}=\mathbf{2 . 5 0}\end{array}$ \\
\hline
\end{tabular}

The experimental work was done through different test cases. The first case is done in a duct without baffles. The other cases are performed with different baffles arrangements, see Table 1. The wall static pressure was measured through $1 \mathrm{~mm}$ diameter pressure taps in the wall along the center plane of duct. The uncertainties in measuring wall pressure led to an uncertainty in the wall static pressure coefficient of \pm 0.009 . The measurements of the static pressure distribution were conducted using multi-tube water manometer. The inflow Reynolds number was determined from the measured flow rate $(Q)$ through a calibrated orifice meter fitted with a mercury U-tube manometer with an accuracy of $1.5 \%$.

The wall pressure distributions are sampled in the form of wall pressure recovery coefficient defined as: $C_{p}=\frac{\bar{p}-\bar{p}_{r e f}}{0.5 \rho U_{i n}^{2}}$, where $\bar{p}_{r e f}$ is the atmospheric pressure and $U_{i n}=\frac{Q}{W \times H}$ is the average velocity at entrance, see El-Askary and Nasr [17].

The thermal energy lost is estimated from a separate heat-loss experiment done on the test facility without air-flow. A heat loss characteristic curve is developed for each thermocouple location. It is found that the maximum local heat flux loss is less than $5 \%$ of the total local heat flux supplied. The heated-wall temperatures are measured directly by the embedded thermocouples. The temperature distributions are expressed in dimensionless form considering the inflow temperature $\left(T_{1}\right)$ to the test section as a reference value. The maximum uncertainty of the measured temperature is within $\pm 2 \%$.

\section{COMPUTATIONAL STUDY}

The computational model used in this study is shown in Fig. 2 where two dimensional, incompressible and turbulent flow of air is considered. The governing equations are discretised using a finite volume method. In the discretisation scheme, control volume cells for velocity components are staggered with respect to the main 
control volume cells using the SIMPLE algorithm developed by Patankar [19]. The QUICK scheme is used to calculate velocity components, $k$ (the turbulence kinetic energy), $\varepsilon$ (its dissipation rate) and energy equations. The set of discretised equations are solved iteratively line-by-line. Computation is started by first solving continuity, momentum, $k$ and $\varepsilon$ equations to determine the flow field and then the energy equation to find the thermal field in the computational domain.

The $k-\varepsilon$ turbulence model is used to compute the eddy viscosity $v_{t}$. In eddy viscosity models (EVMs) the Reynolds stress tensor is modeled by the Boussinesq hypothesis (see Pope [20]) which assumes the turbulent stress to be proportional to the mean strain rate, via an eddy viscosity.

Based on the characteristics scales of $D_{h}, U_{\text {in }}$ and $T_{1}$ the dimensionless variables are defined as follows:

$x=\frac{\bar{x}}{D_{h}}, \quad y=\frac{\bar{y}}{D_{h}}, \quad k=\frac{\bar{k}}{U_{\text {in }}^{2}}, \quad u=\frac{\bar{u}}{U_{\text {in }}}, \quad \mathrm{v}=\frac{\overline{\mathrm{v}}}{U_{\text {in }}}, \quad p=\frac{\bar{p}}{\rho U_{\text {in }}^{2}}, \quad \varepsilon=\frac{\bar{\varepsilon} D_{h}}{U_{\text {in }}^{3}}, \quad \mathrm{v}^{\prime 2}=\frac{\overline{\mathrm{v}^{\prime 2}}}{U_{\text {in }}^{2}}$, $f=\frac{\bar{f} D_{h}}{U_{\text {in }}}, \quad \tau=\frac{\bar{\tau} U_{\text {in }}}{D_{h}}$ and $T=\frac{\bar{T}}{T_{1}}$.

Where the over bar represents the dimensional quantities. According to the above assumptions and dimensionless variables, the dimensionless governing equations for turbulent flow can be expressed as the following equations:

Continuity equation

$$
\left(\frac{\partial u}{\partial x}+\frac{\partial \mathrm{v}}{\partial y}\right)=0
$$

Momentum equations

$$
\begin{aligned}
& u \frac{\partial u}{\partial x}+\mathrm{v} \frac{\partial u}{\partial y}=-\frac{\partial p}{\partial x}+\frac{\partial}{\partial x}\left[\left(\frac{1}{\operatorname{Re}}+\frac{1}{\operatorname{Re}_{t}}\right) \frac{\partial u}{\partial x}\right]+\frac{\partial}{\partial y}\left[\left(\frac{1}{\operatorname{Re}}+\frac{1}{\operatorname{Re}_{t}}\right) \frac{\partial u}{\partial y}\right] \\
& u \frac{\partial \mathrm{v}}{\partial x}+\mathrm{v} \frac{\partial \mathrm{v}}{\partial y}=-\frac{\partial p}{\partial y}+\frac{\partial}{\partial x}\left[\left(\frac{1}{\operatorname{Re}}+\frac{1}{\operatorname{Re}_{t}}\right) \frac{\partial \mathrm{v}}{\partial x}\right]+\frac{\partial}{\partial y}\left[\left(\frac{1}{\operatorname{Re}}+\frac{1}{\operatorname{Re}_{t}}\right) \frac{\partial \mathrm{v}}{\partial y}\right]
\end{aligned}
$$

Energy equation

$$
u \frac{\partial T}{\partial x}+\mathrm{v} \frac{\partial T}{\partial y}=\frac{\partial}{\partial x}\left[\left(\frac{1}{\operatorname{Re} \operatorname{Pr}}+\frac{1}{\operatorname{Re}_{t} \operatorname{Pr}_{t}}\right) \frac{\partial T}{\partial x}\right]+\frac{\partial}{\partial y}\left[\left(\frac{1}{\operatorname{Re} \operatorname{Pr}}+\frac{1}{\operatorname{Re}_{t} \operatorname{Pr}_{t}}\right) \frac{\partial T}{\partial y}\right]
$$

The fluid laminar $(\mathrm{Pr})$ and turbulent Prandtl $\left(\mathrm{Pr}_{t}\right)$ numbers for all calculations are 0.71 and 0.85 ; respectively.

The dimensionless equations for standard k- $\varepsilon$ model are written as: 


$$
\begin{gathered}
u \frac{\partial k}{\partial x}+\mathrm{v} \frac{\partial k}{\partial y}=\frac{\partial}{\partial x}\left[\left(\frac{1}{\operatorname{Re}}+\frac{1}{\sigma_{k} \operatorname{Re}_{t}}\right) \frac{\partial k}{\partial x}\right]+\frac{\partial}{\partial y}\left[\left(\frac{1}{\operatorname{Re}}+\frac{1}{\sigma_{k} \operatorname{Re}_{t}}\right) \frac{\partial k}{\partial y}\right]+P_{k}-\varepsilon \\
u \frac{\partial \varepsilon}{\partial x}+\mathrm{v} \frac{\partial \varepsilon}{\partial y}=\frac{\partial}{\partial x}\left[\left(\frac{1}{\operatorname{Re}}+\frac{1}{\sigma_{\varepsilon} \operatorname{Re}_{t}}\right) \frac{\partial \varepsilon}{\partial x}\right]+\frac{\partial}{\partial y}\left[\left(\frac{1}{\operatorname{Re}}+\frac{1}{\sigma_{\varepsilon} \operatorname{Re}_{t}}\right) \frac{\partial \varepsilon}{\partial y}\right] \\
+c_{1} \frac{\varepsilon}{k} P_{k}-c_{2} \frac{\varepsilon^{2}}{k}
\end{gathered}
$$

where $P_{k}$ is the rate of production of turbulent kinetic energy and is given by:

$$
P_{k}=\frac{2 S^{2}}{\operatorname{Re}_{t}}
$$

and

$$
S^{2}=\frac{1}{2}\left[\left(\frac{\partial \mathrm{v}}{\partial x}+\frac{\partial u}{\partial y}\right)^{2}+2\left(\frac{\partial u}{\partial x}\right)^{2}+2\left(\frac{\partial \mathrm{v}}{\partial y}\right)^{2}\right]
$$

In the previous dimensionless forms of the governing equations, the turbulent Reynolds number $\operatorname{Re}_{t}$ is defined as: $\operatorname{Re}_{t}=U_{i n} D_{h} / v_{t}$. The turbulent (eddy) kinematic viscosity $v_{t}$ is given by the relation:

$$
v_{t}=c_{\mu} \operatorname{Re} \frac{(k)^{2}}{\varepsilon}
$$

The values of the model constants are taken as: $c_{1}=1.44, c_{2}=1.92, \sigma_{k}=1.0$ and $\sigma_{\varepsilon}=1.3$.

Leschziner and Rodi [21] incorporated the effects of streamline curvature in the definition of $c_{\mu}$ in the following form:

$$
c_{\mu}=\operatorname{Max}\left\{0.025, \frac{0.09}{\left[1+0.57 \frac{k^{2}}{\varepsilon^{2}}\left(\frac{\partial V_{t o t}}{\partial n}+\frac{V_{t o t}}{R_{c}}\right) \frac{V_{t o t}}{R_{c}}\right]}\right\}
$$

where, $V_{t o t}=\sqrt{u^{2}+\mathrm{v}^{2}}$, is the total velocity and $n$ is the normal vector to the streamline.

The curvature radius $R_{c}$ can be computed as given by Leschziner and Rodi [21]:

$$
\frac{1}{R_{c}}=\frac{u \mathrm{v}\left(\frac{\partial u}{\partial \bar{x}}-\frac{\partial \mathrm{v}}{\partial \bar{y}}\right)+\mathrm{v}^{2} \frac{\partial u}{\partial y}-u^{2} \frac{\partial \mathrm{v}}{\partial x}}{\left(u^{2}+\mathrm{v}^{2}\right)^{1.5}}
$$


The dimensionless form of dissipation equation for renormalization group model of Velayati and Yaghoubi [22] is written as:

$$
\begin{aligned}
& u \frac{\partial \varepsilon}{\partial x}+\mathrm{v} \frac{\partial \varepsilon}{\partial y}=\frac{\partial}{\partial x}\left[\left(\frac{1}{\operatorname{Re}}+\frac{1}{\sigma_{\varepsilon} \operatorname{Re}_{t}}\right) \frac{\partial \varepsilon}{\partial x}\right]+\frac{\partial}{\partial y}\left[\left(\frac{1}{\operatorname{Re}}+\frac{1}{\sigma_{\varepsilon} \operatorname{Re}_{t}}\right) \frac{\partial \varepsilon}{\partial y}\right] \\
& +c_{1} \frac{\varepsilon}{k} P_{k}-\left(\frac{c_{\mu} \eta^{3}\left(1-\frac{\eta}{\eta_{0}}\right)}{1+\beta \eta^{3}}\right) \frac{\varepsilon^{2}}{k}-c_{2} \frac{\varepsilon^{2}}{k}
\end{aligned}
$$

where $\eta=\sqrt{c_{\mu}^{-1} \frac{P_{k}}{\varepsilon}}$. The values of the model constants are taken as:

$c_{\mu}=0.085, c_{1}=1.44, c_{2}=1.68, \sigma_{k}=1.39, \sigma_{\varepsilon}=1.39, \eta_{0}=4.38$ and $\beta=0.012$. Here the dimensionless turbulent (eddy) kinematic viscosity $v_{t}$ is given by the relation: $v_{t}=c_{\mu} \operatorname{Re} \frac{k^{2}}{\varepsilon}$.

The dimensionless form equation of dissipation rate for the $\mathrm{v}^{\prime 2}-f$ model is written as (Spall et al. [23]);

$$
\begin{aligned}
& u \frac{\partial \varepsilon}{\partial x}+\mathrm{v} \frac{\partial \varepsilon}{\partial y}=\frac{\partial}{\partial x}\left[\left(\frac{1}{\operatorname{Re}}+\frac{1}{\sigma_{\varepsilon} \operatorname{Re}_{t}}\right) \frac{\partial \varepsilon}{\partial x}\right]+\frac{\partial}{\partial y}\left[\left(\frac{1}{\operatorname{Re}}+\frac{1}{\sigma_{\varepsilon} \operatorname{Re}_{t}}\right) \frac{\partial \varepsilon}{\partial y}\right] \\
& +\frac{c_{\varepsilon 1} P_{k}-c_{\varepsilon 2} \varepsilon}{\tau}
\end{aligned}
$$

The dimensionless equations for $\mathrm{v}^{\prime 2}-f$ are given by:

$$
\begin{gathered}
u \frac{\partial \mathrm{v}^{\prime 2}}{\partial x}+\mathrm{v} \frac{\partial \mathrm{v}^{\prime 2}}{\partial y}=\frac{\partial}{\partial x}\left[\left(\frac{1}{\operatorname{Re}}+\frac{1}{\sigma_{\varepsilon} \operatorname{Re}_{t}}\right) \frac{\partial \mathrm{v}^{\prime 2}}{\partial x}\right]+\frac{\partial}{\partial y}\left[\left(\frac{1}{\operatorname{Re}}+\frac{1}{\sigma_{\varepsilon} \operatorname{Re}_{t}}\right) \frac{\partial \mathrm{v}^{\prime 2}}{\partial y}\right] \\
+k f-6 \mathrm{v}^{\prime 2} \frac{\varepsilon}{k} \\
f=L^{2} \frac{\partial^{2} f}{\partial x^{2}}+L^{2} \frac{\partial^{2} f}{\partial y^{2}}+\left(c_{1}-1\right) \frac{\left(\frac{2}{3}-\frac{\mathrm{v}^{\prime 2}}{k}\right)}{\tau}+c_{2} \frac{P_{k}}{k}
\end{gathered}
$$

The expression of dimensionless eddy viscosity is given by: $\mu_{t}=c_{\mu} \operatorname{Re} \mathrm{v}^{\prime 2} \tau$, where $\mathrm{T}$ is a time scale and $L$ is a length scale, which are calculated from the following relations : 
$\tau^{*}=\max \left(\frac{k}{\varepsilon}, 6 \sqrt{\frac{v}{\varepsilon}}\right)$

$\mathrm{L}^{*}=\mathrm{C}_{\mathrm{L}} \max \left(\frac{k^{3 / 2}}{\varepsilon}, c_{\eta}\left(\frac{v^{3}}{\varepsilon}\right)^{1 / 4}\right) ; \quad \mathrm{L}=\min \left(L^{*}, \frac{1}{\sqrt{6} \mathrm{v}^{\prime 2}} \frac{k}{c_{\mu} \sqrt{S^{2}}}\right)$

The closure coefficients for the model are given as:

$\chi=0.6, \quad c_{1}=1.4, \quad c_{2}=0.3, \quad c_{\varepsilon 1}=1.4, \quad c_{\varepsilon 2}=1.9, \quad c_{\eta}=85, \quad c_{\mu}=0.22$,

$c_{L}=0.25, \sigma_{k}=1.0, \quad \sigma_{\varepsilon}=1.3 \quad$ and $c_{\varepsilon 1}^{*}=1.4\left(1+0.045 \sqrt{\frac{k}{\mathrm{v}^{\prime 2}}}\right)$

The boundary conditions for the above set of governing equations are as follows (see Fig. 3):

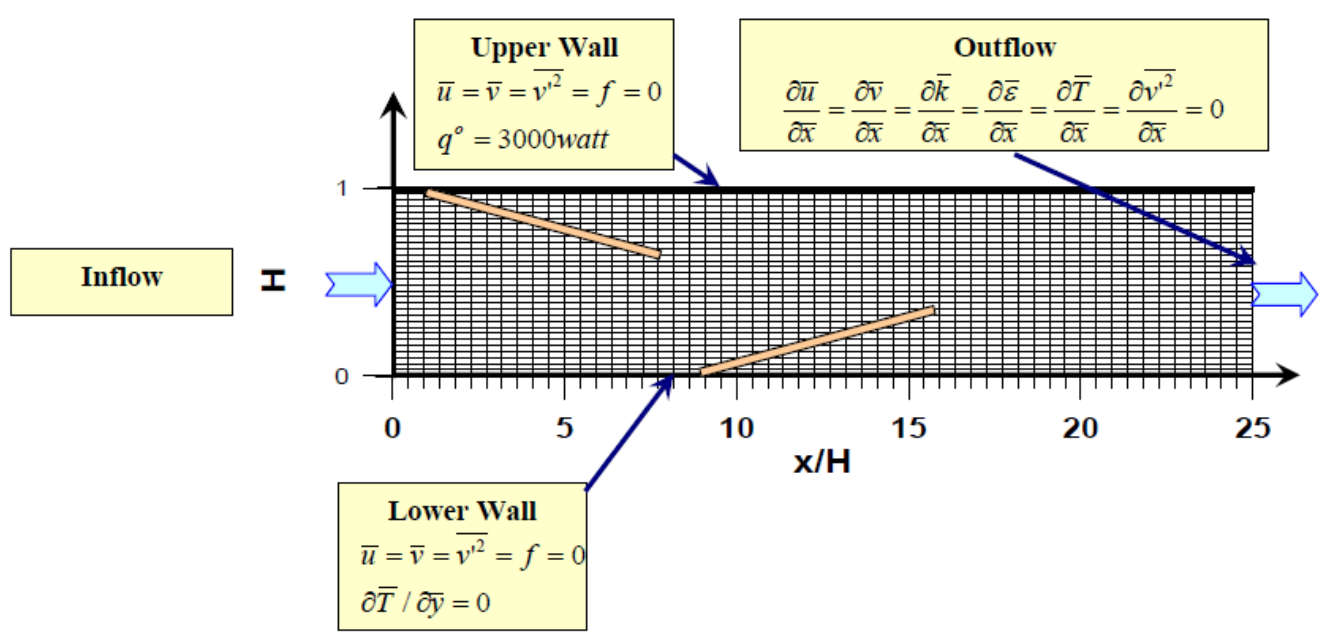

Fig. 3. Grid and boundaries to a duct with two inclined baffles (Not to scale).

\section{Inflow Boundary}

All inflow variables such as velocity, turbulence kinetic energy and its dissipation rate and temperature profiles can be extracted from a two-dimensional RANS computation of an auxiliary smooth duct (inflow generator) of sufficient length to generate a fully developed flow at its exit condition. In the inflow generator, boundary conditions must be also specified. At the inflow; uniform profiles of velocity, turbulent kinetic energy, dissipation rate and temperature are considered, in which $\bar{u}_{i}=U_{i n}$ $, \bar{k}_{i}=0.01 U_{i n}{ }^{2}, \quad \bar{\varepsilon}_{i}=\frac{c_{\mu} \bar{k}_{i}^{1.5}}{0.1 H}, \overline{\mathrm{v}}_{i}^{2}=\frac{2}{3} k_{i}, f_{i}=0.0$ and $\bar{T}_{i}=T_{1}$. All variables are extracted from the exit of the inflow generator and stored to be fed as an inflow to the present case. 


\section{Wall Boundary}

At the walls, the no-slip boundary condition is considered, i.e., $\bar{u}=\overline{\mathrm{v}}=0$ and a constant heat flux, $q^{\circ}=3000$ watt for the upper wall, while $\frac{\partial \bar{T}}{\partial \bar{y}}=0$ for the bottom wall. The velocity, the turbulent kinetic energy and its dissipation rate are modified at the grid points adjacent to the wall by the standard wall function of Launder and Spalding [24].

\section{Boundary Condition on the Baffles}

At the baffles, the no-slip boundary condition is applied on the solid or solid part of perforated baffles, i.e. $\phi=\bar{u}, \bar{v}=\bar{k}=\bar{\varepsilon}=\overline{\mathrm{v}}^{2}=0$ and considering the wall function on the nearest grid points to the walls, considering the normal distance of the grid point to the wall and the velocity component parallel to the wall.

\section{Exit Boundary}

A zero gradient condition is employed for the outlet boundary. Although this boundary condition is strictly valid only when the flow is fully developed, it is also permissible for sufficient downstream from the region of interest, i.e., $\frac{\partial \phi}{\partial x}=0$ and $\phi=\bar{u}, \bar{v}, \bar{T}, \bar{k}, \bar{\varepsilon}$ and $\overline{v^{\prime 2}}$.

\section{SOLUTION PROCEDURE}

The mathematical model described above consists of a set of differential equations subject to appropriate boundary conditions. To provide the algebraic form of the governing equations, a fully staggered grid system is adopted for the velocity components and the scalar variables. These equations are discretised using a control volume method (CVM). The numerical solution in the present work is accomplished using Semi- Implicit Method for Pressure Linked Equation (SIMPLE) utilized by Patankar [19]. The velocity components $\bar{u}$ and $\bar{v}$ are calculated at west and south faces of the main control volumes from the solution of the axial and normal momentum equations. A pressure correction equation is solved; then the velocities and the pressure fields are corrected. To complete iteration, the energy equation and the turbulent kinetic energy and energy dissipation rate are solved successively. The discretisation equations are solved by the line by line procedure, which is a combination of Gauss- Seidel and tridiagonal matrix algorithm (TDMA). Relaxation factors are employed to promote smooth convergence of the discretised equations. The relaxation factors are $0.75,0.75,0.5,0.5,0.5,0.5$ and 0.5 for $\bar{u}, \bar{v}, \bar{p}, \bar{k}, \bar{\varepsilon}, \overline{v^{\prime 2}}$ and $\bar{T}$, respectively. The turbulent viscosity is also underrelaxed at a value of 0.5 . The converged criterion in this study was based on the successive changes in variables. All field variables are monitored, and the following condition is used to declare convergence in the iteration $m$ : 


$$
\operatorname{MAX}\left|\frac{\phi_{i, j}^{m}-\phi_{i, j}^{m-1}}{\phi_{i, j}^{m}}\right| \leq 10^{-5}
$$

In addition, the ratio of the difference between the inlet mass flow rate and the outlet mass flow rate to the inlet mass flow rate is also examined. Convergence is declared if the relative mass imbalance is less than $10^{-3}$ and equation (16) are satisfied simultaneously.

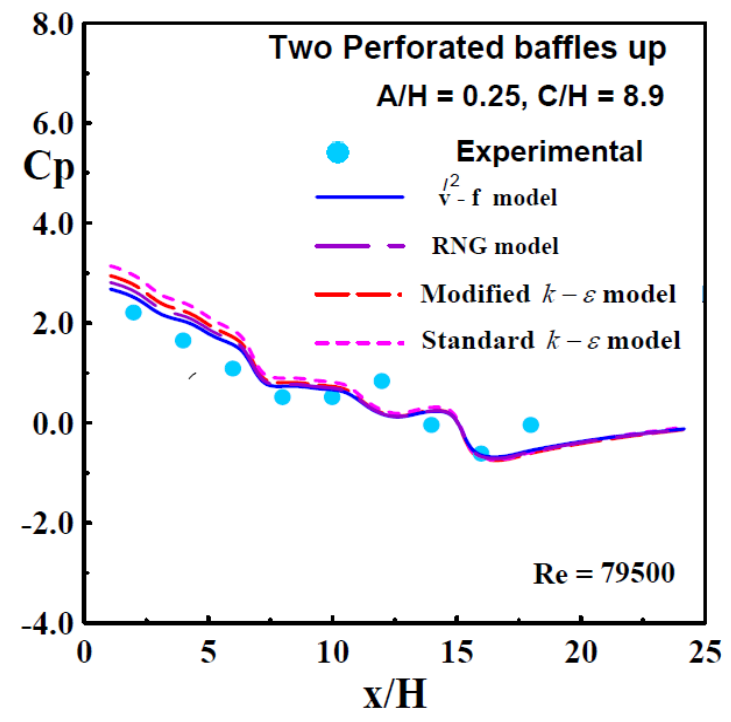

(a)

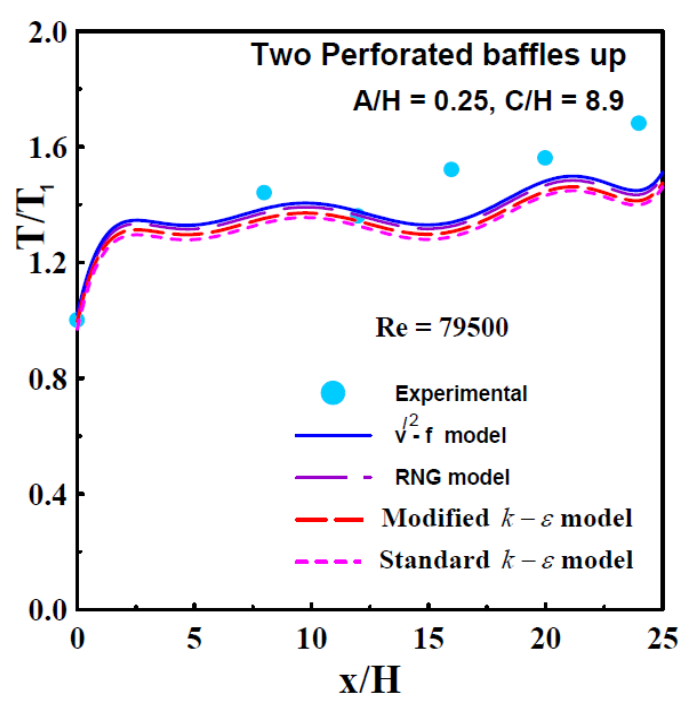

(b)

Fig. 4. Verifications of different turbulence models in case 4: wall-pressure recovery coefficient (a) and wall-temperature distribution (b).

Over the computational domain, the grid points are distributed uniformly in streamwise direction, while in the other direction the non-dimensional near-wall distance $\left(y^{+}=0.8\right)$ is generated and the grid is then expanded towards the duct core with and expansion factor 1.05. A $200 \times 100$ grid points are placed in the computational domain and found to be suitable for computation after different grid tests starting from a rough one $100 \times 50$ to the finest one $400 \times 200$. Validations of the different turbulence models incorporated in the present study are shown in Fig. 4, where the wall-pressure recovery coefficient and wall-temperature distributions are presented. As clearly observed, all models give quite similar results, for $\mathrm{T}$, underestimating measurements by $6 \%$ at the exit of the test-section. This is not surprising, as the same wall-function approach is used for all of the models, and the same model for the plates. However, $\mathrm{v}^{\prime 2}-f$ turbulence model gives the nearest one to the measurements so it will be used in all considered cases in the present simulations. Before going to final decision one should verify the present developed code via validation with published work such as that of Dutta and Hossain [18], see Fig. 5. Different configurations ( $\mathbf{B}$ and $\mathbf{F}$ ) are chosen similar to our case 3 (one perforated baffle on the upper wall and one perforated baffle on the lower wall) with different installation distances. The comparison shows that the present developed code can be used in the present simulations. However, some deviations are observed due to the two-dimensionality assumptions in the present numerical code. 


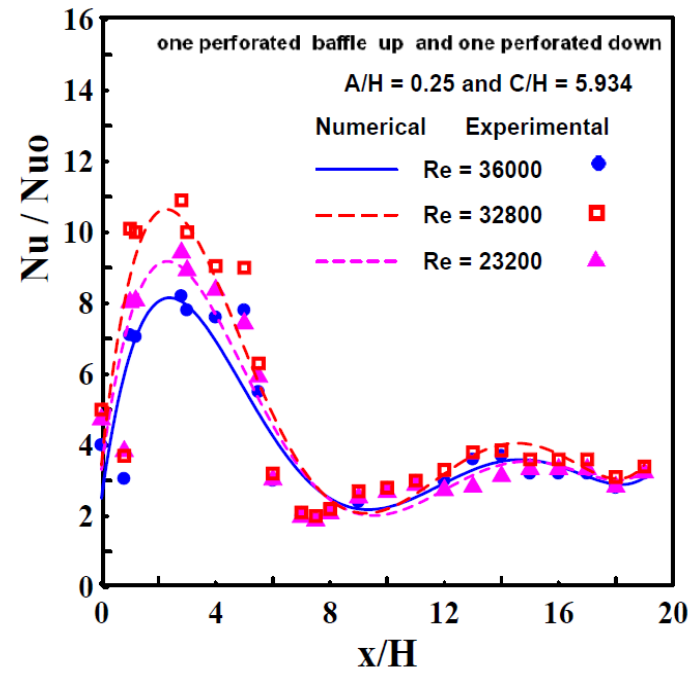

(a) Local Nusselt number distribution along the channel at different Reynolds number: Experimental Configuration B of Dutta and Hossain [18]

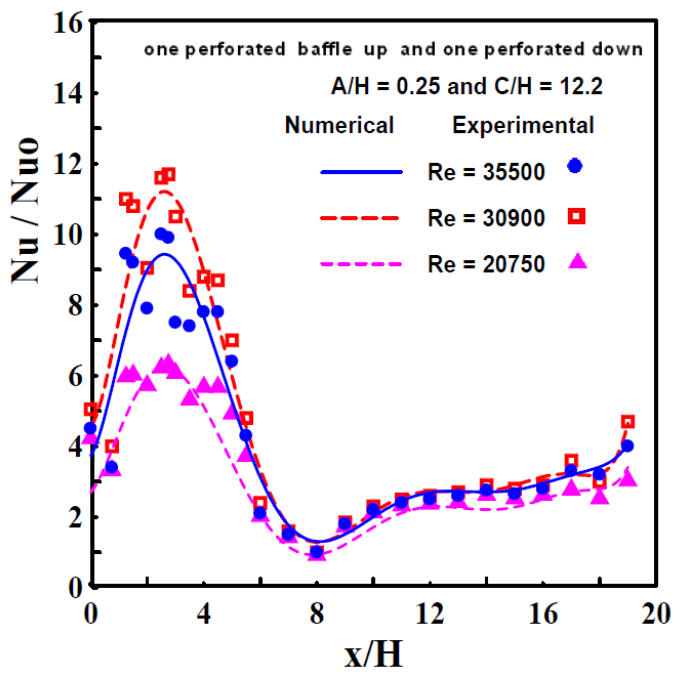

(b) Local Nusselt number distribution along the channel at different Reynolds number:

Experimental Configuration $\mathbf{F}$ of Dutta and Hossain [18]

Fig. 5. Verification of the present computation (lines) using $v^{2}-f$ model via comparison with measurements (symbols) of Dutta and Hossain [18] for different configurations.

\section{RESULTS AND DISCUSSION}

In this section, we represent only the conclusive results from the distributions of lower-face wall pressure as well as the temperature near the inner surface of the upper wall of the duct. A numerical study (using $\mathrm{v}^{\prime 2}-f$ turbulence model) is simultaneously verified through the comparisons with the measurements at different Reynolds numbers: $\left(\operatorname{Re}=\rho U_{i n} D_{h} / \mu=55400,79500\right.$ and 92300, where $D_{h}$ is the hydraulic diameter of the duct) and different configurations and setups of the baffles, see Table 1.

Figure 6 shows the dimensionless pressure (Fig. 6 (a)) and the dimensionless temperature (Fig. 6 (b)) distributions along the corresponding duct walls at the considered different inflow Reynolds numbers including the experimental as well as the numerical data for case 1 (duct without baffles). As noticed from the comparisons, the numerical code is seemly to be a reasonable one to simulate such kind of flow (simple duct flow with heat transfer). However, the deviations may be due to the two-dimensionality considered in the simulation. Generally, for duct flow the pressure decreases in the streamwise direction, while the near surface temperature increases, because of the presence of isoflux source on the upper wall and the developing of the thermal boundary layer on the upper wall inner surface. As the Reynolds number increases one sees that the surface pressure and temperature gradients decrease. The temperature decreases near the exit (in the downstream tangent; $x / H \geq 20$ ), because the flow approach the duct exit atmospheric temperature. 


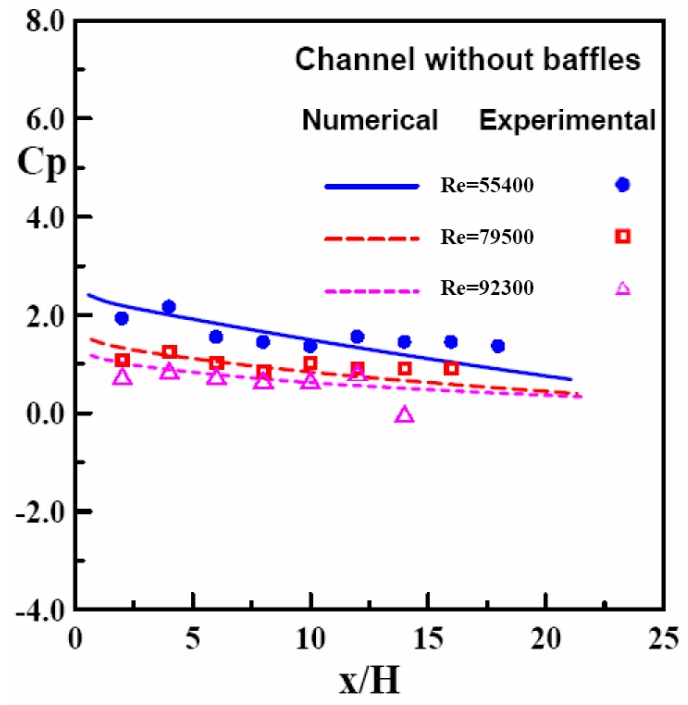

(a)

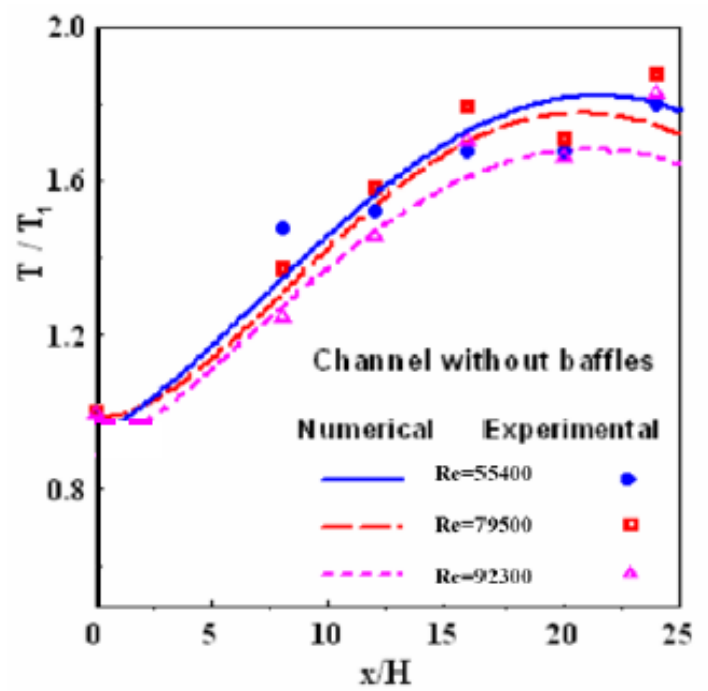

(b)

Fig. 6. Dimensionless pressure (a) and dimensionless temperature (b) distributions along the duct walls at the considered different inflow Reynolds numbers for case 1 . Comparisons of numerical (lines) and experimental (symbols) results.

The presence effect of the baffles in the studied duct starts from Fig. 7, where one baffle is perforated and located on the upper wall (fixed baffle) at dimensionless distance $A / H=0.25$ from the inlet of channel and a second baffle is solid and located on the bottom wall at dimensionless distance $\mathrm{C} / \mathrm{H}=8.9$ from the inlet of channel (case 2 , see Table 1). The plots show the effect of Reynolds number on the pressure recovery coefficient on the insulated lower wall. From Fig. 7(a), it can be seen that the pressure decreases with downstream distance until the location of the second baffle. This is due to the acceleration of flow near the bottom wall with the downstream distance. It fills down suddenly behind the baffle to minimum value and then increases again reaching the reattachment point and it slowly increases to reach the pressure at the duct exit. It may be expected to be an effect of a recirculation zone generated behind the baffle. It is also seen from Fig. 7(a), that the pressure coefficient decreases by increasing Reynolds number. This is because the hydraulic losses are decreasing with increasing Reynolds number. Some deviations are clearly visible directly after the solid baffle location for the lower Reynolds number, because of the strong pressure gradient accompanied by a strong back flow behind the solid baffle.

In Figure 7 (b), the temperature distributions a long the walls at the studied different Reynolds numbers are shown. The temperature increases in the streamwise direction for the lowest Reynolds number case with a sharp increase near the duct entrance because of the presence of the fixed perforated baffle (compare with case 1 without baffle), while with increasing Reynolds number, one observes a reduction of the surface temperature (high heat transfer rate) with approaching the location of the second baffle $(\mathrm{C} / \mathrm{H}=8.9)$, because of the strong jets issued form the perforated baffle and impinge the upper wall with high momentum. The placement of the fixed perforated baffle on the upper wall at the beginning of the heated section $(A / H=0.25)$ disturbs the boundary layer formation and contributes to higher heat transfer. Here 


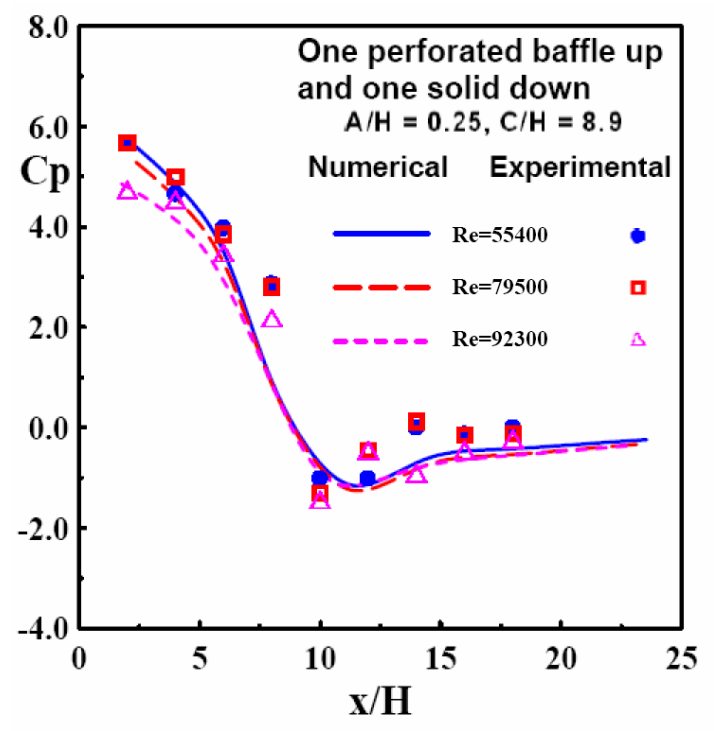

(a)

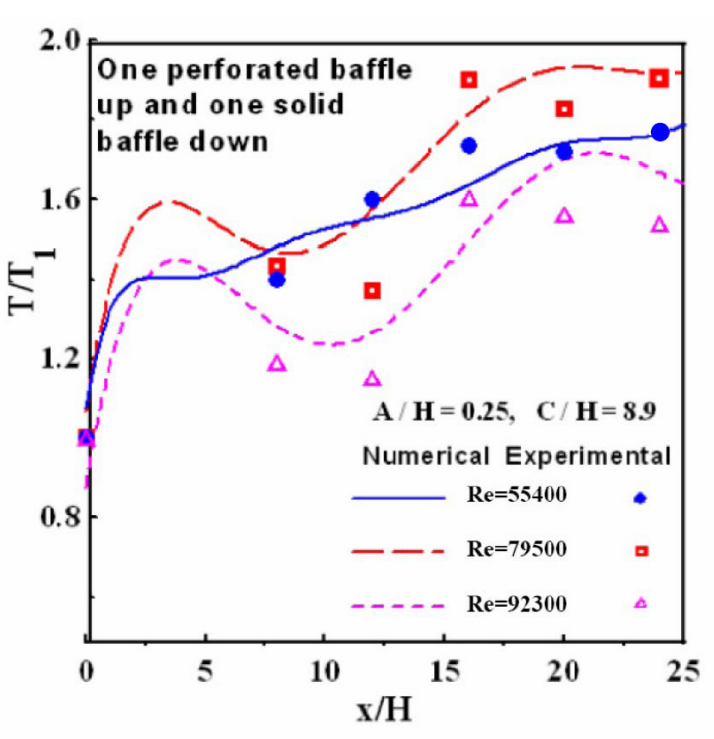

(b)

Fig. 7. Dimensionless pressure (a) and dimensionless temperature (b) distributions along the duct walls at the considered different inflow Reynolds numbers for case 2 . Comparisons of numerical (lines) and experimental (symbols) results.

the second baffle (solid) fixed on the lower wall doesn't allow any flow leakage and it deflects the entire flow towards the heated upper wall. In the present configuration, the fluid faces a convergent section, and hence the velocity of fluid starts increasing near the trailing edge of the first baffle. This contributes to high heat transfer rate. The temperature starts again to increase in the region of the second solid baffle because of the directed entire flow towards the upper wall.

In general, the wall temperature can be seen to rise rapidly from inlet till the first baffle is encountered. With the encounter of the baffle, the plate temperature is reduced significantly indicating a high rate of heat transfer in this region. This depression is more pronounced in the present case of solid baffle at higher Reynolds numbers because the flow reattachment practically destroys the laminar sublayer. This effect does not extend too far from the reattachment region and the plate temperature rises again due to the redevelopment of the laminar sublayer. Reasonable comparisons between the experimental and numerical results are noticed in Fig. 7.

For case 3 , where the first fixed perforated baffle is kept in its location, while the solid baffle in case 2 is replaced by a perforated one, see Fig. 8 . Figure 8 (a) shows the relation between the pressure recovery coefficient and the dimensionless downstream distance at bottom wall of the channel. From this Figure, it can be seen that the trend of the pressure recovery coefficient is same like that trend of the pressure in Fig. 7 (a), but with lower values of pressure and mild adverse pressure gradient behind the second baffle. This is due to the flow leakages which pass through the holes in the second baffle in the form of jets which cause a reduction of pressure loss due to the baffle obstruction. As noticed, the increasing of Reynolds number causes a decrease of wall-pressure values. That can be seen from the experimental and numerical data. The temperature distributions for case 3 are 
experimentally and numerically presented in Fig. 8 (b) at the studied Reynolds numbers.

However, the presence of the second perforated baffle instead of the solid one give better heat transfer rate for all studied Reynolds numbers. This is observed from the lowering peak of wall temperature, which moves downstream with increasing the Reynolds number. The difference in the behavior of the solid and perforated baffles can be attributed to the different flow structures for the two cases. In the case of the solid baffles, there is separation of the flow at the baffles and its reattachment downstream the baffles. The laminar sublayer is practically completely destroyed at the point of reattachment. However, a zone of recirculation appears behind the baffle and there is local heat removal by the shedding of vortices only. The acceleration produced by the baffles also contributes to the heat transfer enhancement. In the case of perforated baffles, a part of the flow passes through the holes in the baffle reducing or eliminating the hot zone.

In the present case of the perforated baffles (one up and one down), the turbulence created by the jet-like flow is probably not capable of destroying the laminar sublayer completely, hence there is a smaller depression in the wall temperature. But the effect of the turbulence extends significantly in the axial direction, and hence the wall temperature mildly increases till the next baffle is encountered. The next depression in the temperature takes place with the encounter of the second baffle. The wall temperature variation pattern after the second baffle is the same as after the first for the case 2 (solid baffle). The wall temperature variation for the perforated baffles indicates the effectiveness of these baffles. The numerical results still reproduce the experimental data obtained for case 3 in Fig. 8.

The pressure and temperature distributions obtained from the experimental as well as the numerical data for case 4 at the same different Reynolds numbers are given in Fig. 9. The presence of two perforated baffles on the upper wall only decreases the pressure values compared with cases 2 and 3 . A milder pressure gradient without any adverse pressure gradient on the lower wall is noticed, because of the absence of baffles on such wall; see Fig. 9 (a). The heat transfer behavior is represented in the form of the dimensionless wall temperature for case 4, which is given in Fig. 9 (b). Different lowering peaks of temperature, showing heat transfer augmentation, are observed and this leads in general to a reduction of the near wall temperature.

Comparisons between the results of the four cases, including pressure and temperature distributions at $\mathrm{Re}=55400$, are considered in Fig. 10. As noticed from Fig. 10 (a), the pressure distribution for case 4 approaches that obtained from case 1 (duct without baffles) and hence a lower energy loss along the duct length can be obtained from case 4 compared with cases 2 and 3 . On the other hand, the temperature distribution along the upper wall (Fig. 10 (b)) shows that also case 4 produces the best performance at the given Reynolds number $(R e=55400)$, in which the highest heat transfer can be obtained by installing two perforated baffles on the upper wall. Case 2, in which a perforated baffle is installed on the upper wall and another solid baffle is installed on the lower wall, doesn't show any heat transfer improvements, because the solid baffle presses the flow towards the upper wall of the duct and hence the thermal boundary layer decreases and no chance to transfer 


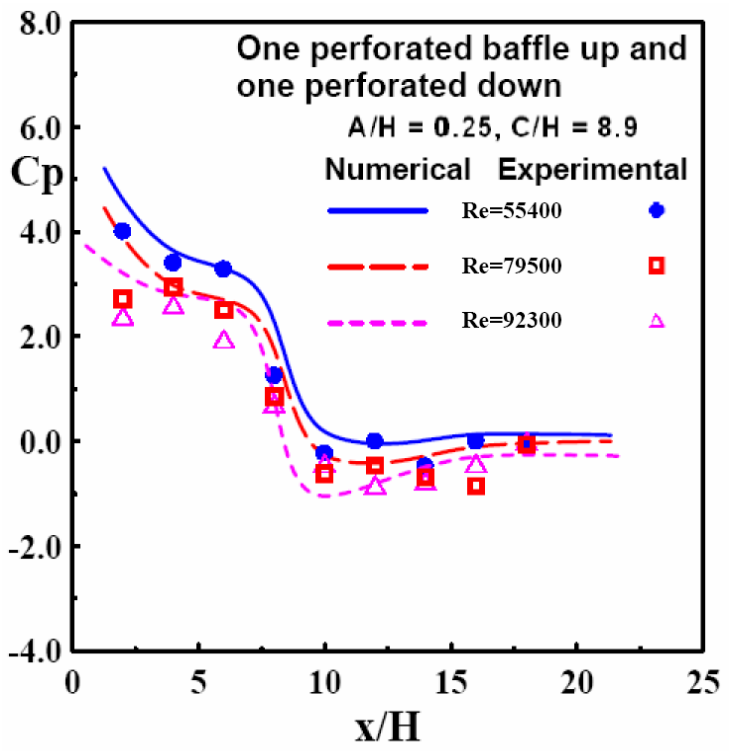

(a)

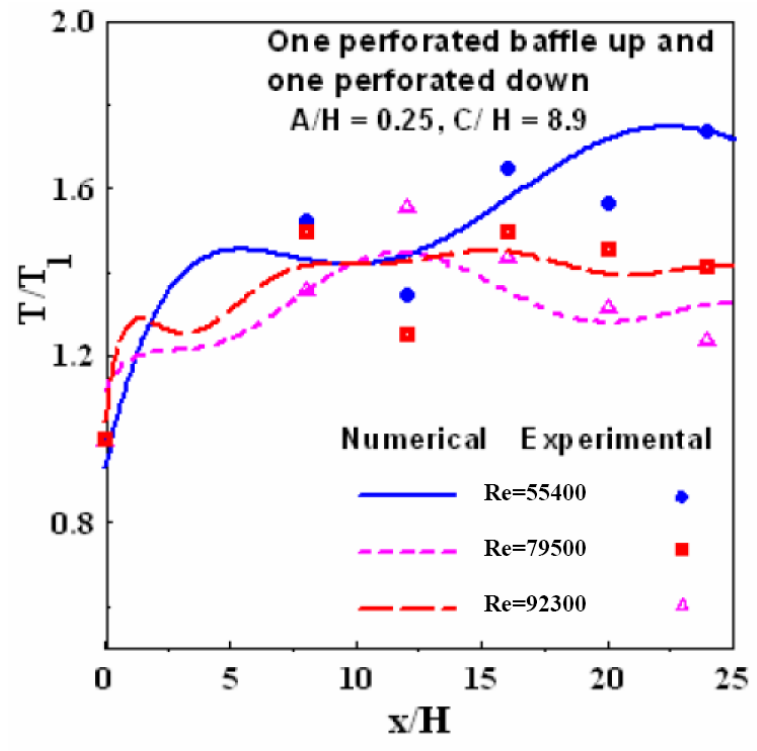

(b)

Fig. 8. Dimensionless pressure (a) and dimensionless temperature (b) distributions along the duct walls at the considered different inflow Reynolds numbers for case 3 . Comparisons of numerical (lines) and experimental (symbols) results.

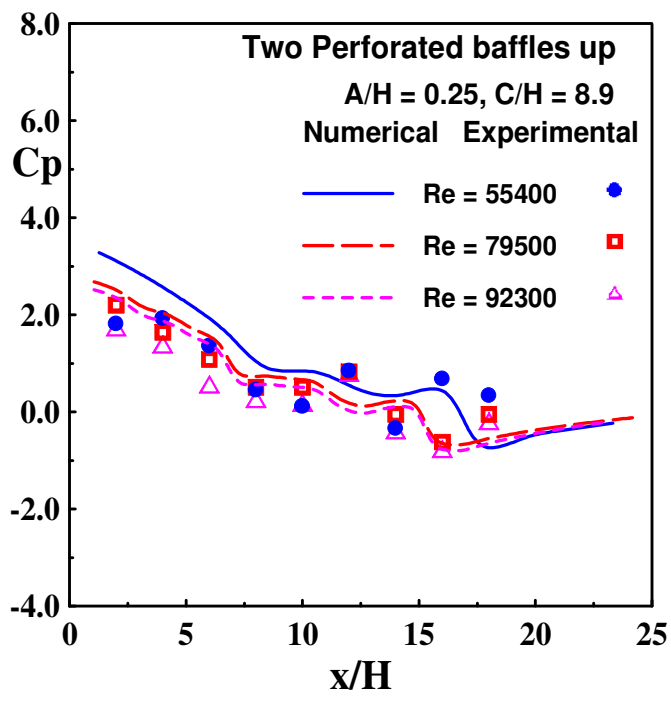

(a)

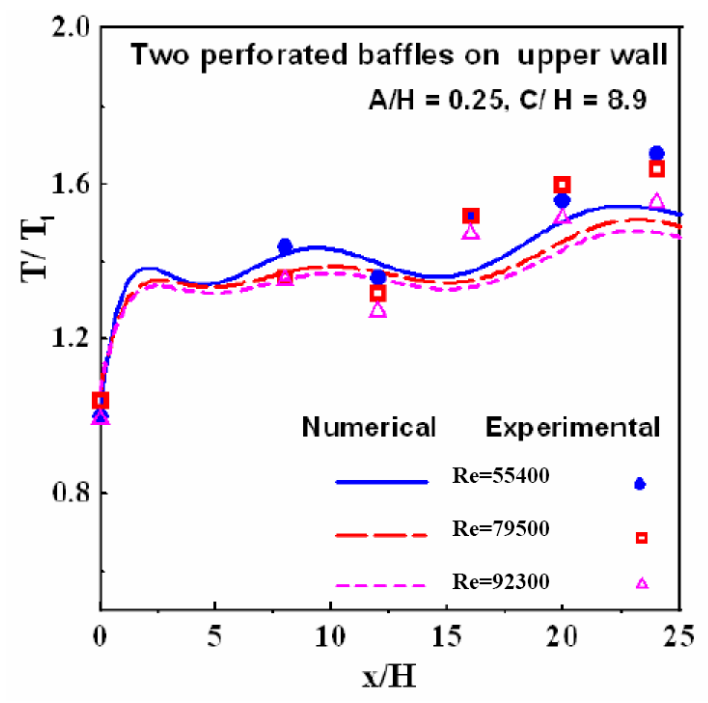

(b)

Fig. 9. Dimensionless pressure (a) and dimensionless temperature (b) distributions along the duct walls at the considered different inflow Reynolds numbers for case 4. Comparisons of numerical (lines) and experimental (symbols) results.

heat to the core flow. In case 3, the presence of perforated baffle instead of the solid one in case 2 causes some improvements near the mid-length of the duct. This can be seen directly after the position of the second perforated baffle $(C / H=8.9)$ to a distance after its edge position, because of the presence of a recirculation zone behind it. These results may be changed at higher Reynolds numbers (discussed later). 


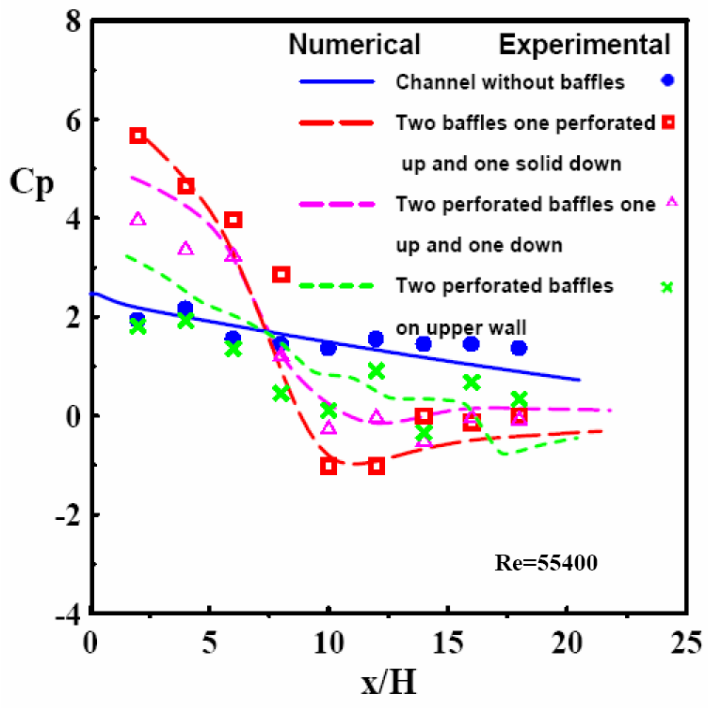

(a)

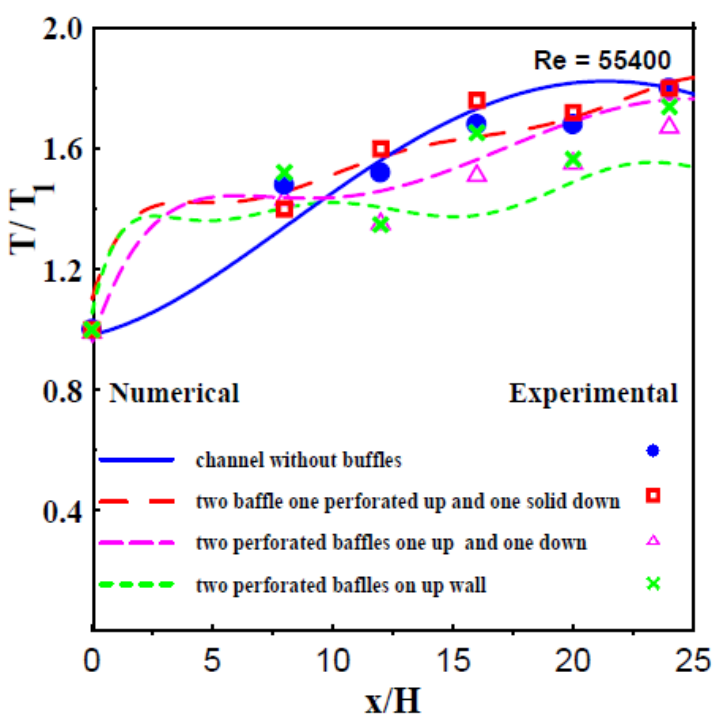

(b)

Fig. 10. Comparisons between the four cases results of pressure distribution (a) and temperature distribution (b) at $\mathrm{Re}=55400$. Numerical data (lines) and experimental data (symbols).

The effect of using the baffles on the pressure drop across the tested duct for all studied cases at different Reynolds numbers is shown in terms of the friction factor ratio $\left(f_{c} / f_{c}\right.$ (smooth), where $f_{c}$ is the friction factor of the studied case and $f_{c}$ (smooth) is the friction factor of a duct without baffles) as represented in Fig. 11. This ratio can be estimated from the pressure drop $\Delta C_{p}$, which is the difference between the values of inlet and outlet wall pressure recovery coefficient, as the following form:

$$
\frac{f_{c}}{f_{c}(\text { smooth })}=\frac{\Delta C_{p}}{\Delta C_{p}(\text { smooth })}
$$

The losses mainly come from the dissipation of the dynamical pressure of the air due to high viscous losses near the wall, to the extra forces exerted by reverse flow and to higher friction of increasing surface area and the blockage because of the presence of the baffles. Over the range of the Reynolds number studied, the friction factor ratio increases with Reynolds number for all cases. In the figure, it is apparent that the use of baffles leads to a substantial increase in pressure drop over the smooth channel. This can be attributed to flow blockage, higher surface area and the presence of reverse flow. As expected, the pressure drop obtained from case 2 is substantially higher than that from cases 3 and 4, because of the strong flow blockage created by the presence of the solid baffle on the lower wall of the duct. Over the range of the studied Reynolds number, the perforated baffles can reduce the pressure drop of the duct effectively related to the solid baffles (compare case 4 with the other cases). The friction factor increases significantly because of the form drag. In the case of perforated baffles, a part of the flow passes through the holes in the baffle reducing or eliminating the hot zone and form drag. The jet like flow through the holes of the baffles interacts with the reattaching and accelerating flow passing over the baffles. The effect of the reattachment is somewhat reduced but the 
flow through the perforations creates turbulence at the wall which causes a decrease in the thickness of the laminar sublayer and mixing of the fluid near the wall with the turbulent core and hence; the friction decreases. As discussed previously, case 4 still produces the best performance of baffled duct, in which the pressure drop is the lowest one compared with the other cases of baffled duct over the studied range of Reynolds number. However, the comparisons between the measured and computed friction factor ratios show good validation of the computational method.

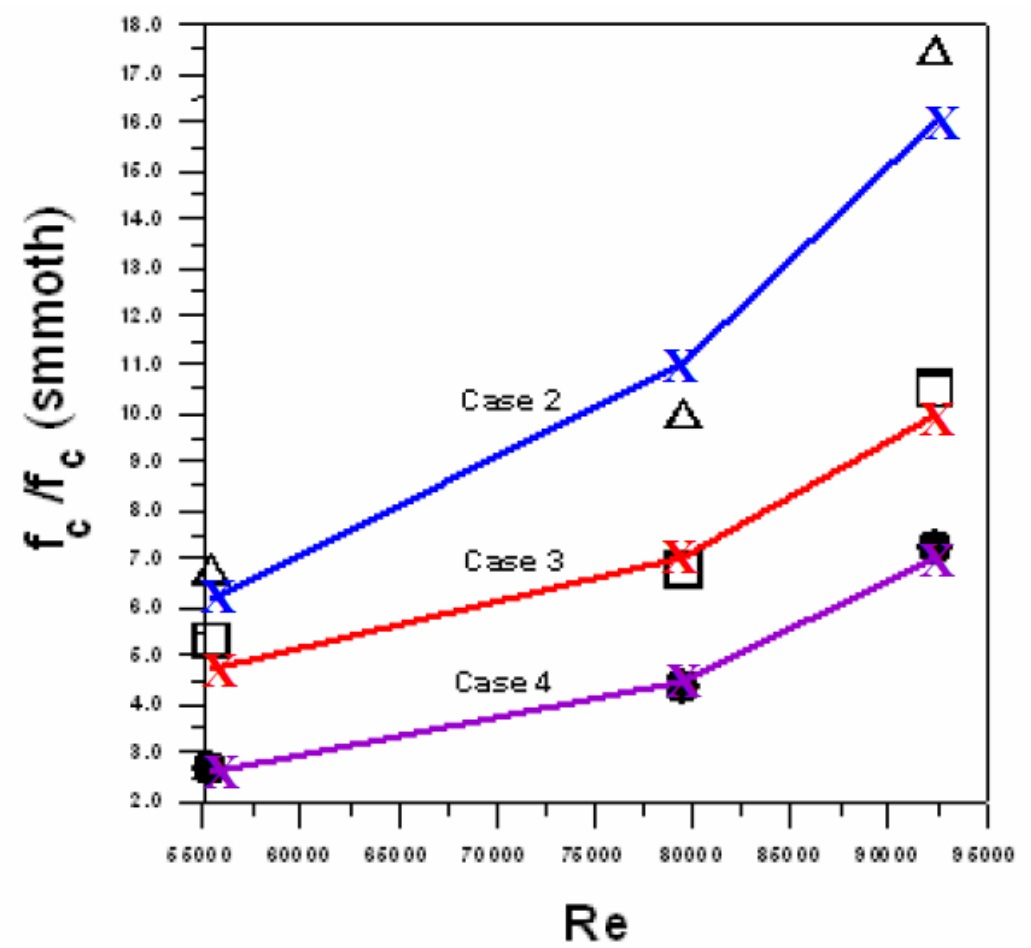

Fig. 11. Effect of using the baffles on the friction factor ratio across the tested duct for cases 2, 3 and 4 against Reynolds numbers. Numerical data (connected crosses) and experimental data (symbols).

Figure 12 shows the dimensionless temperature difference $\left(\Delta T / T_{1}\right)$, where $\Delta T$ is the temperature difference between the duct exit and inlet. As noticed, for Case 1, the range of Reynolds number variations doesn't strongly affect the temperature drop in the along the duct length. At the lowest Reynolds number $(R e=55000)$, the presence of perforated baffle on the upper wall and a solid one on the lower wall (case 2) causes a very small temperature drop, while the middle $R e$ increases the temperature difference and that means that for such Reynolds number $(R e=79000)$, the thermal performance of the duct drops. This may be due to the presence of a strong recalculating bubble behind the solid baffle, which directs the flow strongly towards the upper heated wall and hence reduces the thickness of the developed wall jet behind the perforated baffle on the upper wall. This leads to a reduction of heat transfer at such Reynolds number. With increasing Reynolds number $(R e=92300)$, heat transfer improvement is noticed again for such case (case 2) via decreasing of the temperature difference. The increasing of Reynolds number is responsible for a reduction of the back recirculation bubble and hence gives a chance to increase the wall-jet thickness leading to increased heat transfer from the wall. 
For case 3, the temperature difference strongly decreases with Reynolds number giving the best thermal performance at the middle and the highest Reynolds number compared with all other cases, while at the lowest Reynolds number this thermal performance approaches that can be obtained from case 2 . The temperature difference slightly decreases against Reynolds number for case 4, but the best thermal performance for such case can be obtained at the lowest Reynolds number $(\mathrm{Re}=55000)$. Generally, the perforated baffles with the difference locations can produce the best thermal performance compared with the presence of a solid baffle instead of a perforated baffle. Thus, the perforated baffles enhance the heat transfer rate with a much lower pressure loss penalty as compared to the solid baffles. However, perforated baffles in addition to the heat transfer improvements and lowering the pressure drop; they have considerable reduction in weight by comparison with solid baffles.

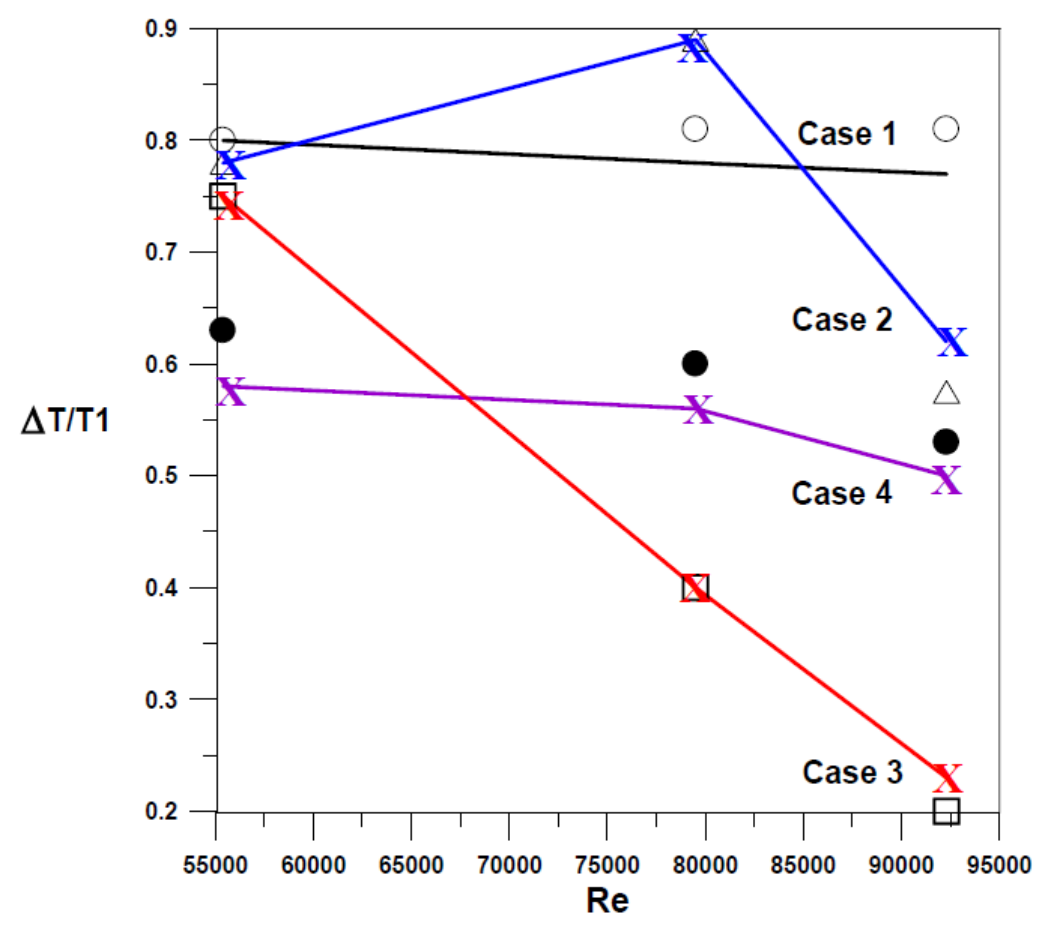

Fig. 12. Effect of using the baffles on the temperature drop across the tested duct for all cases against Reynolds numbers. Numerical data (connected crosses) and experimental data (symbols).

The impact of the baffle orientation on the structure of the near wall flow is depicted in Figs. 13 and 14. The plots in these Figures show the streamwise velocity and turbulence kinetic energy contours, respectively, for different baffle orientations at $\mathrm{Re}$ $=79500$ using the numerical results of the present modified $\mathrm{k}-\varepsilon$ turbulence.

A representative selection of streamwise velocity contours $\left(\bar{u} / U_{\text {in }}\right)$ and the location of first perforated baffle $(\mathrm{A} / \mathrm{H}=0.25)$ and the second baffle at $\mathrm{C} / \mathrm{H}=8.9$ with baffle angle $\left(\theta=5^{\circ}\right)$ is shown in Fig. 13. The results of the considered baffled duct cases (cases 2, 3 and 4) are shown here for isothermal (a, c and e in the figure) as well as the presence of heat transfer cases (b, $d$ and $f$ in the figure). In all cases, a strong vortex is observed downstream of the baffle, which is induced due to the flow separation. 


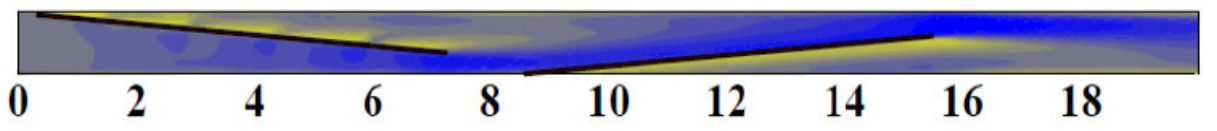

(a)

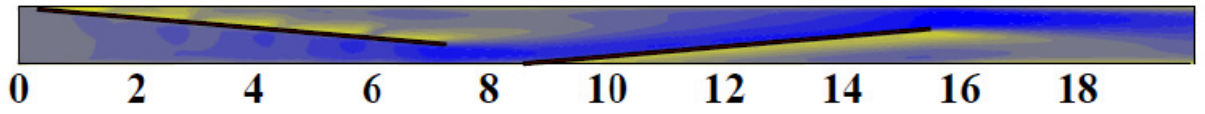

(b)
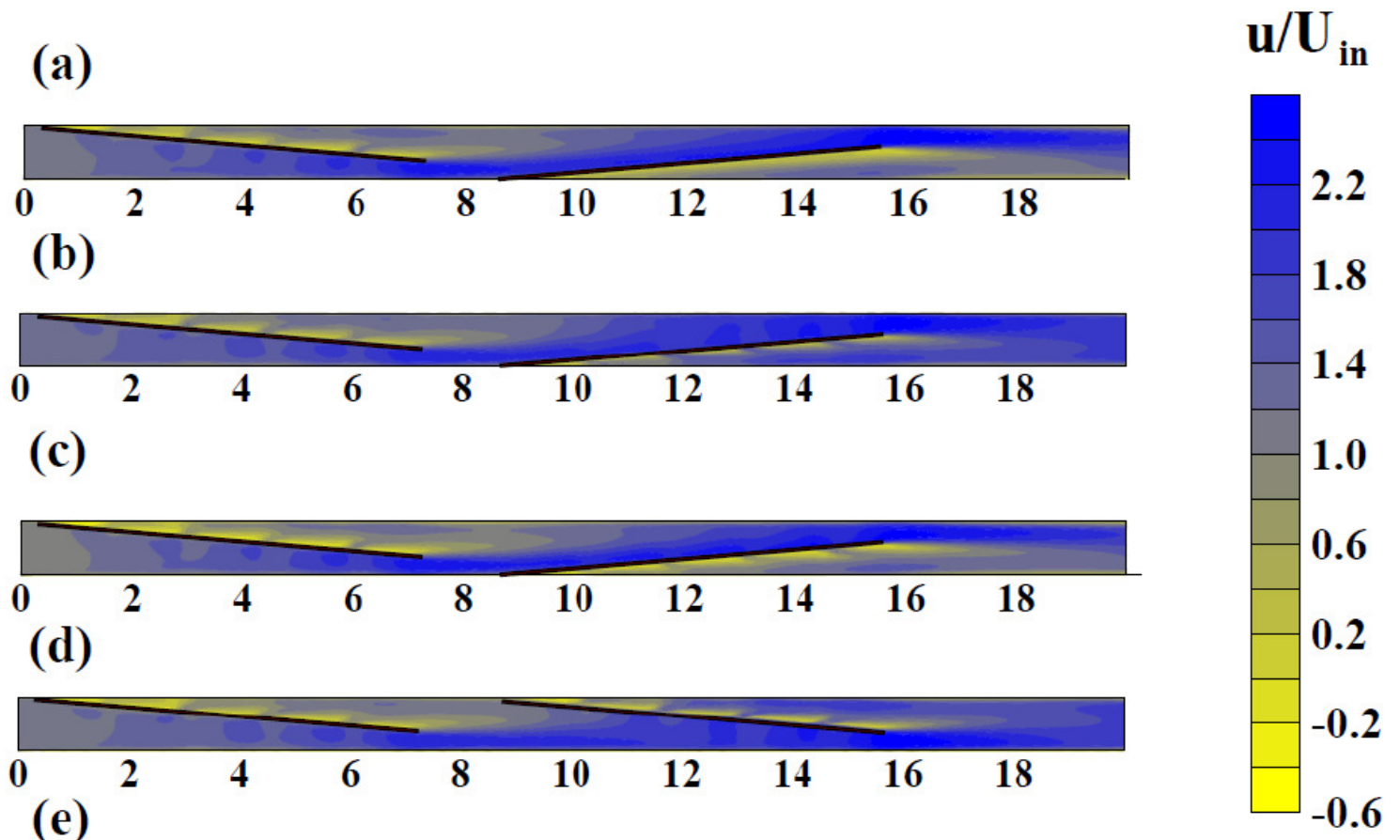

(c)

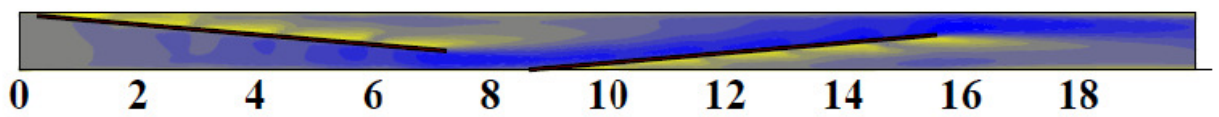

(d)

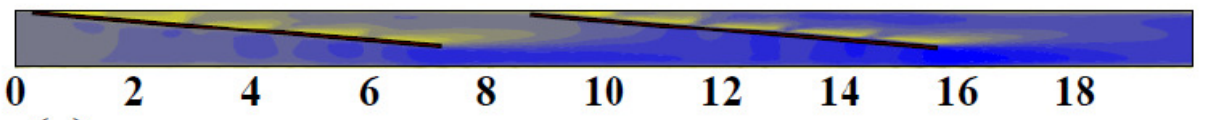

(e)

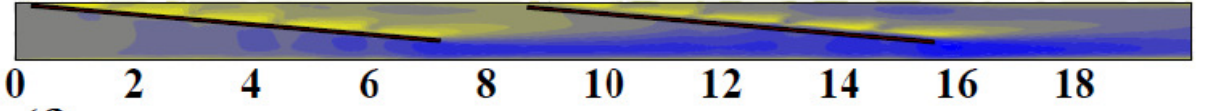

(f)

Fig. 13. Effects of absence (a, $c$ and $e$ ) and presence (b, $d$ and $f)$ of heat transfer on the dimensionless streamwise-velocity contours $\left(\bar{u} / U_{i n}\right)$ in the duct at $\operatorname{Re}=79500$ for different cases: case 2 (a \& b), case 3 (c \& d) and case 4 (e \& f).

The vortex is located close to the solid wall and its height was approximately equal to the extent of the flow blockage by the baffle. From this Figure, it can be seen that the velocity gradient concentrates in the gap between the two baffles and the flow passages from the holes as jets forms in the perforated baffle. Five recirculation zones generate behind all perforated baffles used for isothermal and thermal fluid flow. A single big-recirculation zone appears behind the second solid baffle (case 2) at the same location as shown in Fig. 13 ( $a$ and $b$ in the figure). As noticed the back flow for the isothermal flow case (Fig. 13 (a)) starts upstream of the solid baffle, because of the presence of a strong pressure gradient generated by the presence of solid baffle. With the presence of heat transfer, the fluid particles carry much more energy to overcome the early backflow upstream of the solid baffle (Fig. 13 (b)). The size of the recirculation zone is smaller for the case of second perforated baffle instead of the solid baffle (case 3); see Fig. 13 (c and d). This is because the second solid baffle does not allow any flow jets and it deflects the entire flow toward the upper wall, while the second perforated baffle installed at the same location $\mathrm{C} / \mathrm{H}=8.9$ on the lower wall allows some fluid flow through the perforation holes and hence can 
reduce the recirculation zone. As noticed, the recirculation zones behind the perforated baffle increase with the presence of heat transfer. The results of case 4 are also presented in Fig. 13 (e and f) for isothermal and with heat transfer fluid flow, respectively. The results show that the baffle form- and orientation has an effect on the length and the magnitude of the separation bubble behind it. The comparison of the recirculation zone size for different baffle orientations shows that the perforated baffles generate the shortest recirculation zones. However, the presence of heat transfer, cause noticeable elongation of recirculation zones behind the baffles, because of the energy transfer from the upper wall to the fluid in such region, which cause a strong activation of the back flow.

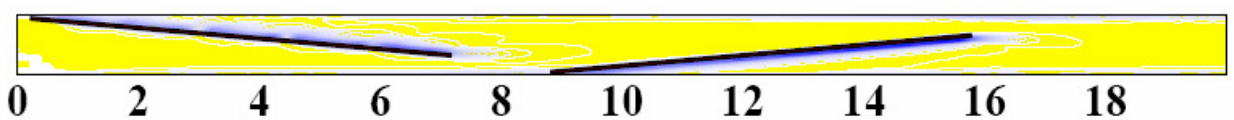

(a)

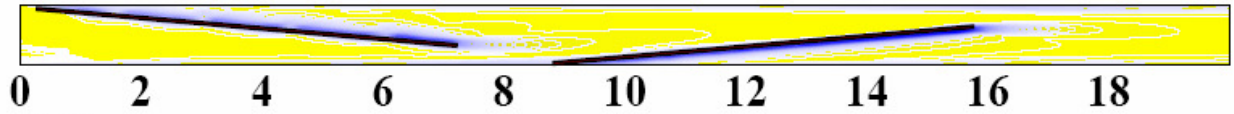

(b)

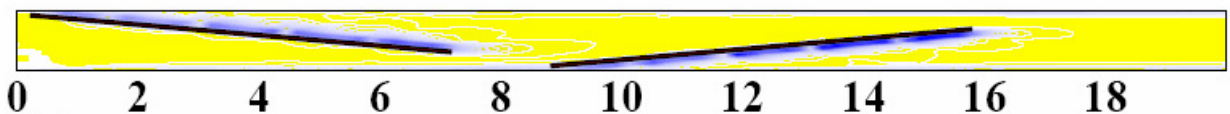

(c)

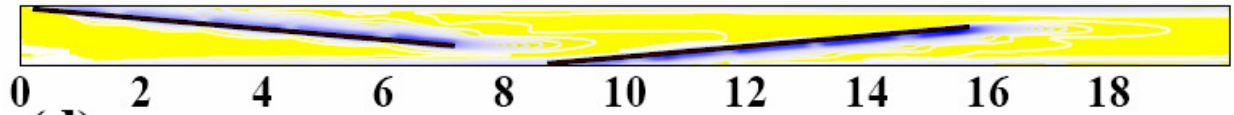

(d)

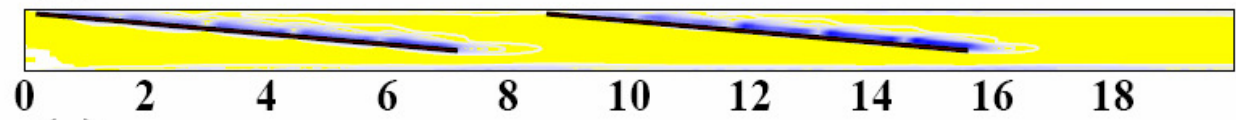

(e)

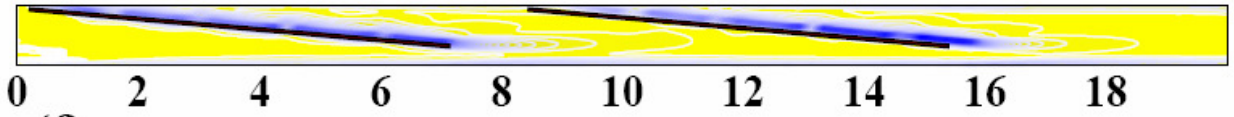

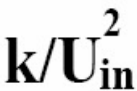

0.50

0.45

0.40

0.35

0.30

0.25

0.20

0.15

0.10

0.05

0.00

(f)

Fig. 14. Effects of absence (a, $c$ and $e)$ and presence (b, $d$ and f) of heat transfer on the dimensionless turbulence kinetic energy contours $\left(\bar{k} / U_{\text {in }}\right)$ in the duct at $R e=79500$ for different cases: case 2 (a \& b), case 3 (c \& d) and case 4 (e \& f).

In Figure 14, the contours of the dimensionless turbulence kinetic energy $\left(\bar{k} / U_{\text {in }}^{2}\right)$ for cases considered in Fig. 13 are numerically represented. As shown the turbulence energy is enhanced at all edges of baffles with the presence of heat transfer due to the transported energy to the flow from the upper heated wall. The enhancement of turbulence kinetic energy is also clearly observed in the recirculation zones behind the perforated as well as the solid baffles. 


\section{CONCLUSIONS}

This paper discusses experimental and numerical results for heat transfer and pressure drop of turbulent fluid flow in a rectangular duct with two inclined baffles. A constant heat flux is applied from the upper surface of the channel, while other surfaces are maintained isolated. Different cases are considered: case 1 (without baffles), case 2 (one perforated baffle on the upper wall and one solid baffle on the lower wall), case 3 (one perforated baffle on the upper wall and one perforated baffle on the lower wall) and case 4 (two perforated baffles on the upper wall). The flow Reynolds number is varied between 55,400 and 92,300, and the baffle forms (solid or perforated) and orientations are varied to obtain a wide range of results. The heat transfer and pressure distribution results are presented in non-dimensional ratios $T / T_{1}$ (local temperature to the inlet temperature) and $C_{p}$ (wall pressure recovery coefficient), respectively. Enhancement of the heat transfer from the upper surface of the duct flow by the attachment of perforated and perforated/solid baffles has been investigated as function of the flow and geometrical parameters. Pressure drop corresponding to the heat-transfer enhancement have also been measured and computed. Main conclusions emerging from the present study are as follows:

1- The $\mathrm{v}^{\prime 2}-f$ turbulence model can be effectively used in the computation of recirculating flow produced by the presence of inclined baffles in a duct with presence of heat transfer.

2- The local temperature ratio and wall pressure recovery with two inclined baffles significantly depends on the arrangement (perforation and orientation of the baffles) used. Two inclined baffles augment the local heat transfer coefficient for a longer region of interest and increases significantly the pressure drop compared with the smooth duct (case 1). The using of perforated baffles can reduce the pressure drop of the duct effectively related to the solid baffles.

3- In all arrangements, the friction factor ratio increases with increase in the flow Reynolds number. For case 2, the frictional head loss is much higher than that of the other arrangements and case 4 produces the lowest head loss.

4- The local non-dimensional temperature difference is a weak function of flow Reynolds number for cases 1 and 4, while it varies strongly with Reynolds number in cases 2 and 3.

In a following study, the authors intend to check the ability of the non-linear turbulence models as well as Large-Eddy Simulation to simulate the present cases with the presence of wall roughness in a three-dimensional unsteady flow.

\section{REFERENCES}

[1] Dutta, P., Dutta, S., Effect of Baffle Size, Perforation and Orientation on Internal Heat Transfer Enhancement, Int. J. Heat Mass Transfer, Vol. 41, No. 19, pp. 3005-3013, (1998).

[2] Berner, C., Durst, F., McEligot, D.M., Flow Around Baffles, ASME J. Heat Transfer, Vol. 106, pp. 743-749, (1984). 
[3] Habib, M. A., Mobarak, A. M., Sallak, M.A., Abdel Hadi, E.A., Affify, R.I., Experimental Investigation of Heat Transfer and Flow over Baffles of Different Heights, ASME J. Heat Transfer, 116(2), 363-368, (1994).

[4] Lin, C.W., Experimental Study of Thermal Behaviors in a Rectangular Channel with Baffle of Pores, Int. Commun. Heat Mass Transfer, Vol. 33, pp. 985-992, (2006).

[5] Kurtbas, I., The Effect of Different Inlet Conditions of Air in a Rectangular Channel on Convection Heat Transfer: Turbulence Flow, Experimental Thermal and Fluid Science, Vol. 33, pp. 140-152, (2008).

[6] Chandra, P.R., Alexander, C.R., Han, J.C., Heat Transfer and Friction Behaviors in Rectangular Channels with Varying Number of Ribbed Walls, Int. Journal of Heat and Mass Transfer, Vol. 46, pp. 481-495, (2003).

[7] Karwa, R., Maheshwari, B.K., Heat Transfer and Friction in an Asymmetrically Heated Rectangular Duct with Half and Fully Perforated Baffles at Different Pitches, International Communications in Heat and Mass Transfer, Vol. 36, pp. 264-268, (2009).

[8] Shaeri, M.R., Yaghoubi, M., Numerical Analysis of Turbulent Convection Heat Transfer from an Array of Perforated Fins, International Journal of Heat and Fluid Flow, 30, 218-228, (2009).

[9] Ooi, A., laccarino, G., Durbin, P.A., Behnia, M., Reynolds Averaged Simulation of Flow and Heat Transfer in Ribbed Ducts, International Journal of Heat and Fluid Flow, Vol. 23, pp. 750-757, (2001).

[10] Nasiruddin, M.H., Siddiqui, K., Heat Transfer Augmentation in a Heat Exchanger Tube Using a Baffle, International Journal of Heat and Fluid Flow, Vol. 28, pp. 318-328, (2007).

[11] Nie, JH., Chen, YT., Hsieh, HT., Effects of a Baffle on Separated Convection Flow Adjacent to Backward-Facing Step, International Journal of Thermal Sciences, Vol. 48, pp. 618-625, (2001).

[12] Luviano-Ortiz, L., Hernandez-Guerrero, A., Rubio-Arana, C., RomeroMendez, R., Heat Transfer Enhancement in a Horizontal Channel by the Addition of Curved Deflectors, International Journal of Heat and Mass Transfer, Vol. 51, pp. 3972-3984, (2008).

[13] Gajusingh, S.T., Shaikh, N., Siddiqui, K., Influence of a Rectangular Baffle on the Downstream Flow Structure, Experimental Thermal and Fluid Science, Vol. 34, pp. 590-602, (2010).

[14] Kwankaomeng, S., Promvonge, P., Numerical Prediction on Laminar Heat Transfer in Square Duct with $30^{\circ}$ Angled Baffle on one Wall, International Communications in Heat and Mass Transfer, Vol. 37, No. 7, pp. 857-866, (2010).

[15] Promvonge, P., Heat Transfer and Pressure Drop in a Channel with Multiple $60^{\circ}$ V-Baffles, International Communications in Heat and Mass Transfer, Vol. 37, No. 7, pp. 835-840, (2010).

[16] Nasr, M., Abdel-Fattah, A., El-Askary, W.A., Study of Turbulent Flow in Rectangular Channel with Inclined Baffles, Engineering Research Journal, Faculty of Engineering, Menoufiya University, Vol. 32, No. 2, pp. 131-143, (2009).

[17] El-Askary, W. A., Nasr, M., Performance of a Bend-Diffuser System: Experimental and Numerical Studies, J. Computers \& Fluids, Vol. 38, No. 1, pp. 160-170, (2009). 
[18] Dutta, P., Hossain, A., Internal Cooling Augmentation in Rectangular Channel Using Two Inclined Baffles, International Journal of Heat and Fluid Flow, Vol. 26, pp. 223-232, (2005).

[19] Patankar, S.V., Numerical Heat Transfer and Fluid Flow, McGraw-Hill, New York, U.S.A., (1983).

[20] Pope, S.B. Turbulent Flows, Cambridge University Press, (2000).

[21] Leschziner, M.A., Rodi, W. Calculation of Annular and Twin Parallel Jets Using Various Discretisation Schemes and Turbulence-Model Variations, ASME J. Fluids Eng., Vol. 103, pp. 352-360, (1981).

[22] Velayati, E., Yaghoubi, M. Numerical Study of Convective Heat Transfer from an Array of Parallel Bluff Plates, International Journal of Heat and Fluid Flow, Vol. 26, pp. 80-91, (2005).

[23] Spall, R.E., Richards, A., McEligot., D., An Assessment of $k-\omega$ and $\mathrm{v}^{\prime 2}-f$ Turbulence Models for Strongly Heated Internal Gas Flows, Numerical Heat Transfer part A, Vol. 46, pp. 831-849, (2004).

[24] Launder, B.E., Spalding, D.B., The Numerical Computation of Turbulent Flows, Computer Methods in Applied Mechanics and Engineering, Vol. 3, pp. 269-289, (1974). 